\title{
High Vacuum Measurements and Calibrations, Molecular Flow Fluid Transient Effects
}

\author{
Robert A. Leishear, PhD, P. E. \\ robert.leishear@srnl.doe.gov \\ Savannah River Nuclear Solutions \\ Savannah River Site \\ Aiken, SC, 29808
}

\author{
Nickolas A. Gavalas \\ nickolas.gavalas@srnl.doe.gov \\ Savannah River National Laboratory \\ Savannah River Site \\ Aiken, SC, 29808
}

\begin{abstract}
High vacuum pressure measurements and calibrations below $\approx 1 \times 10^{-6}$ Torr are problematic. Specifically, measurement accuracies change drastically for vacuum gauges when pressures are suddenly lowered in vacuum systems. How can gauges perform like this? To answer this question, a brief system description is first required. Calibrations were performed using a vacuum calibration chamber with attached vacuum gauges. To control chamber pressures, vacuum pumps decreased the chamber pressure while nitrogen tanks increased the chamber pressure. By balancing these opposing pressures, equilibrium in the chamber was maintained at selected set point pressures to perform calibrations. When pressures were suddenly decreased during set point adjustments, a sudden rush of gas from the chamber also caused a surge of gas from the gauges to decrease the pressures in those gauges. Gauge pressures did not return to equilibrium as fast as chamber pressures due to the sparse distribution of gas molecules in the system. This disparity in the rate of pressure changes caused the pressures in different gauges to be different than expected. This discovery of a new theory was experimentally proven to show that different gauge designs return to equilibrium at different rates, and that gauge accuracies vary for different gauge designs due to fluid transients in molecular flow.
\end{abstract}

\section{KEYWORDS}

Fluid transient, molecular flow, ion gauge, spinning rotor gauge, capacitance diaphragm gauge, cold cathode gauge, vacuum measurement, vacuum calibration, vacuum measurement errors.

\section{INTRODUCTION}

Research was performed in high vacuum systems at Savannah River Standards Laboratory (SRSL) in South Carolina using several different types of vacuum gauges, which included spinning rotor gauges (SRG's), capacitance diaphragm gauges (CDGs), ion gauges (IGs), and cold cathode gauges (CCGs). Although performance of each gauge design varied, a symptomatic problem was observed when calibrations were performed. The accuracies of all gauges were

This manuscript has been authored by Savannah River Nuclear Solutions, LLC under Contract No. DE-AC09-08SR22470 with the U.S. Department of Energy. The United States Government retains and publisher, by accepting this article for publication, acknowledges that the United States Government retains a non-exclusive, paid-up, irrevocable, worldwide license to publish or reproduce the published form of this work, or allow others to do so, for United States Government purposes. 
affected when pressures in the system were suddenly decreased to low vacuum pressures. Accuracies of different gauges were compared through testing and by evaluating the uncertainties for different gauges, where multiple gauges were installed while measuring vacuums. To understand this phenomenon, discussions of uncertainty and high vacuums along with system and gauge descriptions are required to introduce test results and the analysis of data. Numerous tests were performed for this investigation to understand process anomalies and ensure reproducibility of results. Only a representative selection of data from this research is presented.

Material and test equipment numbers (M\&TE numbers) for gauges are provided for identification and traceability to original research data, but have little direct application to this presentation.

SRSL operates in accordance with ANSI/ISO 17025 [1] and is accredited by the National Voluntary Laboratory Accreditation Program (NVLAP) for vacuum calibration services, as well as other calibration services.

\section{ABBREVIATIONS AND SYMBOLS}

$A$

$A C T$

$C$

$C C G$

$C D G$

$d$

IG

ISO

$k$

$L$

$\mathrm{M} \& \mathrm{TE}$

$N$

NIST

PSL

$p_{1}$

$p_{2}$

$R D G$

RSS

SRG

SRNL

SRSL

$U$

$u_{S Y S}$
Cross sectional tubing area

Actual, or true, value for a measured quantity, or vacuum reading

Conductance

Cold cathode gauge

Diaphragm gauge

Tubing inside diameter

Ion gauge

International Standards Organization

Coverage factor

Pipe length

Material and test equipment

Number of measurements in a series

National Institute of Standards and Technology

Primary Standards Laboratory

Upstream pressure

Downstream pressure

Reading shown on vacuum controller display

Square root of the sum of the squares for several, or numerous, variables

Spinning rotor gauge

Savannah River National Laboratory

Savannah River Standards Laboratory

Total uncertainty

An uncertainty for a vacuum system 


$\begin{array}{ll}u_{R E F} & \text { An uncertainty for standards } \\ u_{U U T} & \text { An uncertainty for a gauge to be calibrated } \\ U_{R E F} & \text { Expanded uncertainty for standards } \\ U_{U U T} & \text { Expanded uncertainty for gauges to be calibrated } \\ U U T & \text { Unit under test } \\ V & \text { Initial velocity } \\ \mathrm{V} & \text { Valve } \\ \sigma & \text { Standard deviation } \\ \mu & \text { Mean value for a series of measurements }\end{array}$

\section{UNCERTAINTY ANALYSIS}

Uncertainty analysis was integral to this study and was performed in accordance with established uncertainty techniques available in JCGM 100 [2]. Details of uncertainty analysis that were performed for this study are largely excluded from this discussion, but uncertainties are mentioned as applicable to gauge performance. A $k$ value of two is used for SRSL calibrations. For $k=2$, the confidence level equals $95.45 \%$. A value of $k=2$ is recommended by the National Institute of Standards and Technology, NIST [3], and the American Society of Mechanical Engineers, ASME [4].

\subsection{Standard Deviation}

The standard deviation, $\sigma$, determines the variation of a series of $N$ values, or measurements, from their mean value, $\mu$ [5]. For vacuum measurements, these statistical values are the actual, or true, calculated $A C T$ values. To obtain true values, measured readings, $R D G$, are first read directly from vacuum gauge controller displays. These measured values are then mathematically manipulated using Excel ${ }^{\circledR}$ spread sheets to obtain the actual values, as shown in Table 1.

The equations used to calculate $A C T$ values were supplied by the Primary Standards Laboratory, PSL, in Sandia, New Mexico. PSL calibrated ion gauges, and CDGs for SRSL. For example, the actual values for some of the measurements calculated from a CDG (M\&TE number: SL-457K) were determined from the equation,

$A C T=9.62 \times R D G^{1}-5.09 \times R D G^{2}+1.99 \times R D G^{3}$.

As another example, the actual values for an ion gauge (M\&TE number: SL-457U) were determined as

$$
\begin{aligned}
A C T= & 3.53 \times R D G+1.86(\log R D G)+0.49 \times(\log R D G)^{2}+0.06 \times(\log R D G)^{3} \\
& +0.002 \times(\log R D G)^{4} .
\end{aligned}
$$

Once the true values were determined, the mean and the standard deviation were expressed as 
$\mu=\frac{\sum_{i=1}^{N} A C T_{i}}{N}$, and

$$
\sigma=\sqrt{\frac{\sum_{i=1}^{N} \mu-A C T_{i}}{N-1}}
$$

Equation 4 describes the standard deviation that is based on the symmetrical normal distribution, which is frequently referred to as a bell shaped curve.

\begin{tabular}{|c|c|c|c|c|c|c|}
\hline $\begin{array}{l}\text { Nominal } \\
\text { Target }\end{array}$ & $\begin{array}{l}\text { SL-457U, } \\
\text { Display Torr }\end{array}$ & $\begin{array}{l}\text { SL-457U, } \\
\text { Actual Torr }\end{array}$ & $\begin{array}{l}\text { SL-457T, } \\
\text { Display Torr }\end{array}$ & $\begin{array}{l}\text { SL-457T, } \\
\text { Actual Torr }\end{array}$ & $\begin{array}{l}\text { Difference, } \\
\% \text { of Reading }\end{array}$ & $\begin{array}{l}\text { Pressure } \\
\text { Change }\end{array}$ \\
\hline $1.41 \mathrm{e}-8$ & $2.4900 \mathrm{E}-08$ & 2.4344E-08 & $1.270 \mathrm{E}-08$ & 1.2227E-08 & 49.7738 & Increasing \\
\hline $2.38 e-8$ & $3.3900 \mathrm{E}-08$ & $3.3108 \mathrm{E}-08$ & $2.050 \mathrm{E}-08$ & 1.9736E-08 & 40.3899 & Increasing \\
\hline $4.63 e-8$ & $5.9500 \mathrm{E}-08$ & 5.8111E-08 & $4.650 \mathrm{E}-08$ & 4.4755E-08 & 22.9847 & Increasing \\
\hline $1.61 \mathrm{e}-7$ & $1.6600 \mathrm{E}-07$ & 1.6267E-07 & $1.510 \mathrm{E}-07$ & 1.4537E-07 & 10.6343 & Increasing \\
\hline $4.86 \mathrm{e}-7$ & $5.1700 \mathrm{E}-07$ & $5.0838 \mathrm{E}-07$ & 4.970E-07 & $4.7886 \mathrm{E}-07$ & 5.8069 & Increasing \\
\hline $1.16 \mathrm{e}-6$ & $1.1500 \mathrm{E}-06$ & $1.1308 \mathrm{E}-06$ & 1.130E-06 & $1.0889 \mathrm{E}-06$ & 3.7048 & Increasing \\
\hline $4.81 \mathrm{e}-6$ & $5.3400 \mathrm{E}-06$ & 5.2147E-06 & $5.260 \mathrm{E}-06$ & 5.0632E-06 & 2.9048 & Increasing \\
\hline $1.09 e-5$ & $1.0200 \mathrm{E}-05$ & 9.9149E-06 & $1.000 \mathrm{E}-05$ & $9.6246 \mathrm{E}-06$ & 2.9280 & Increasing \\
\hline $4.68 e-5$ & $4.4300 \mathrm{E}-05$ & 4.2767E-05 & 4.330E-05 & 4.2001E-05 & 1.7903 & Increasing \\
\hline $9.73 e-5$ & $9.2600 \mathrm{E}-05$ & 8.9681E-05 & $9.220 \mathrm{E}-05$ & 9.0727E-05 & 1.1674 & Increasing \\
\hline $4.68 e-5$ & $4.4300 \mathrm{E}-05$ & 4.2767E-05 & $4.310 \mathrm{E}-05$ & $4.1804 \mathrm{E}-05$ & 2.2496 & Decreasing \\
\hline $1.09 e-5$ & $4.3000 \mathrm{E}-05$ & $4.1512 \mathrm{E}-05$ & $4.200 \mathrm{E}-05$ & 4.0724E-05 & 1.8964 & Decreasing \\
\hline $1.16 \mathrm{e}-6$ & $1.6200 \mathrm{E}-06$ & 1.5917E-06 & 1.570E-06 & $1.5128 \mathrm{E}-06$ & 4.9598 & Decreasing \\
\hline $4.86 e-7$ & $3.8900 \mathrm{E}-07$ & $3.8230 \mathrm{E}-07$ & 3.590E-07 & 3.4583E-07 & 9.5392 & Decreasing \\
\hline $1.61 \mathrm{e}-7$ & $1.9000 \mathrm{E}-07$ & $1.8629 \mathrm{E}-07$ & $1.670 \mathrm{E}-07$ & $1.6079 \mathrm{E}-07$ & 13.6894 & Decreasing \\
\hline $4.63 e-8$ & $6.3300 \mathrm{E}-08$ & $6.1830 \mathrm{E}-08$ & $4.730 \mathrm{E}-08$ & 4.5524E-08 & 26.3715 & Decreasing \\
\hline $2.38 \mathrm{e}-8$ & $3.7100 \mathrm{E}-08$ & $3.6228 \mathrm{E}-08$ & 2.360E-08 & $2.2719 \mathrm{E}-08$ & 37.2886 & Decreasing \\
\hline $1.41 \mathrm{e}-8$ & $3.0200 \mathrm{E}-08$ & $2.9503 \mathrm{E}-08$ & 1.560E-08 & $1.5019 \mathrm{E}-08$ & 49.0922 & Decreasing \\
\hline
\end{tabular}

Table 1. Typical calibration data (M\&TE numbers: SL-457U and SL-457T). 


\subsection{Uncertainty}

The total expanded uncertainty $(U)$ is used for SRSL calibrations, and $U$ includes uncertainties associated with the installed reference calibration standards, $u_{r e f}$, combined with the uncertainties of the gauge being calibrated, $u_{U U T}$, and the uncertainties of the system response, $u_{S Y S}$, which includes temperature effects, other instrumentation uncertainties, gas properties, flow rate effects, etc. The uncertainty is expressed as

$U=k \cdot \sqrt{\sum u_{R E F}^{2}+\sum u_{U U T}^{2}+\sum u_{S Y S}^{2}}$,

where more detail for calculating uncertainties are available in references JCGM 100 [2], ISO 3567 [6], and ISO 27893 [7].

To determine $U$, the expanded uncertainty $\left(U_{r e f}\right)$ is used for SRSL calibrations and equals the coverage factor $(k)$ times the square root of the sum of the squares $(R S S)$ of the standard uncertainties $\left(u_{R E F}\right)$ for the identifiable Type A and Type B components of error in the measurement process. Standard uncertainties that are statistically derived (i.e., standard deviations, $\sigma$ ) are identified as Type A uncertainties. Standard uncertainties that are non-statistically derived (i.e., engineering judgment, manufacturer's specs, handling effects, environmental conditions, uncertainties from calibration certificates, and estimates of drift) are identified as Type B uncertainties. Accordingly, both accuracy and precision are tacitly included in the expanded uncertainty. For this research, an important fact is that if the accuracy improves, the uncertainty improves. The expanded uncertainty is expressed as

$U_{r e f}=k \cdot \sqrt{\sum u_{R E F}^{2}}$.

Similarly, for gauges to be calibrated and for comparisons to SRSL standards,

$U_{U U T}=k \cdot \sqrt{\sum u_{U U T}^{2}}$.

\section{VACUUM CONCEPTS}

If required, aspects of vacuum systems pertinent to this study can be described through a definition of terms and systems as described by $\operatorname{Varian}{ }^{\circledR}[8]$.

\subsection{Conversion Factors}

Torr are the common units used by national laboratories, such as PSL, SRSL, and their customers. Appropriate conversion factors for vacuum are:

1 atmosphere $=760$ Torr 
100 Pascals $=100$ Newtons $/$ meter $^{2}=1$ millibar $=0.75$ Torr

1 Torr $=1$ millimeter of $\mathrm{Hg}$ (mercury)

1 millitorr $=1$ micron of $\mathrm{Hg}$

\subsection{High Vacuum}

Higher vacuums have lower absolute pressures, i.e., the lower the pressure, the higher the vacuum. The system used for this research has a high vacuum limit, or lowest operating pressure, of approximately $1 \times 10^{-8}$ Torr, as measured by ion gauges. Pressures occasionally lower to approximately $9 \times 10^{-9}$ Torr, but these lower pressures are attributed to a pumping action of ions known to occur in ion gauges when these gauges operate continuously without system pressure changes.

\subsection{Mean Free Path}

The mean free path depends on the molecular density, where these two variables are related in Table 2 [9]. Note that at $7.6 \times 10^{-6}$ Torr, molecules travel for 6.5 meters before hitting another molecule. Accordingly, pressure in molecular flow is not a primary driver for flow.

\begin{tabular}{|c|c|c|}
\hline Pressure & Molecules per centimeter & Mean Free Path, meters \\
& & $6.5 \times 10^{-8}$ \\
\hline 760 Torr $(1$ atmosphere $)$ & $2.5 \times 10^{19}$ & $6.5 \times 10^{-5}$ \\
\hline $7.6 \times 10^{-1}$ Torr & $2.5 \times 10^{16}$ & $6.5 \times 10^{-3}$ \\
\hline $7.6 \times 10^{-3}$ Torr & $2.5 \times 10^{14}$ & 6.5 \\
\hline $7.6 \times 10^{-6}$ Torr & $2.5 \times 10^{11}$ & $6.50 \times 10^{5}$ \\
\hline $7.6 \times 10^{-11}$ Torr & $2.5 \times 10^{6}$ & \\
\hline
\end{tabular}

Table 2. Mean free path, molecular density and vacuum pressures. 


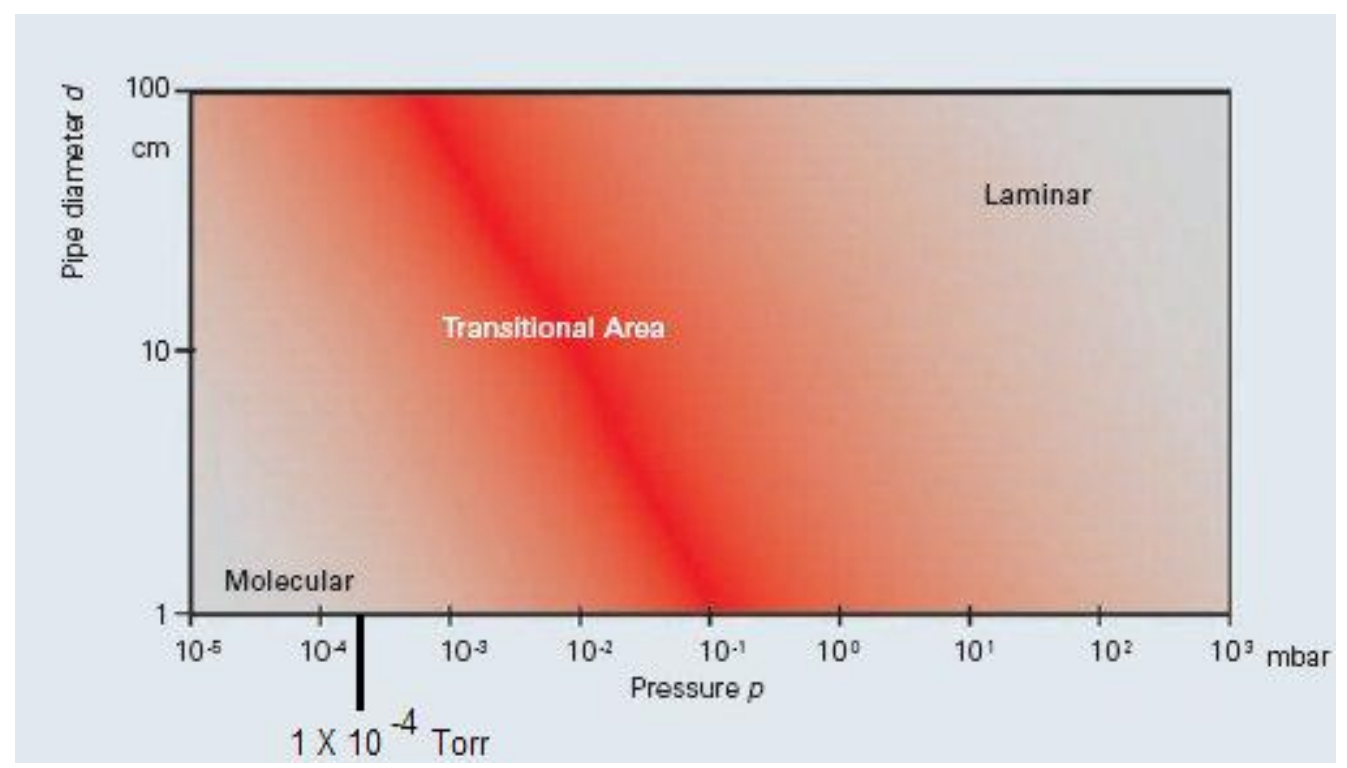

Figure 1. Types of flow in vacuum systems [10] (Reprinted by permission of Oerlikon Leybold Vacuum).

\subsection{Conductance}

Conductance describes flow in vacuum systems and quantifies the ability of tubing to allow a given volume of gas to pass through in a given time. Pfeiffer Vacuum provides a graph (Fig. 1) to describe different types of flow in vacuum systems, i.e., laminar, transitional, and molecular. For the research performed here, test pressures were all below $1 \times 10^{-4}$ Torr, which means that all flows in tubing were molecular. At high vacuums, molecular flow occurs due to the random motion of molecules, where long mean free paths result in molecules striking the tubing walls more often than striking other molecules. Leybold Vacuum [11] provides an equation to find conductance, $C$, in tubing, such that

$C=\frac{135 \cdot d^{4} \cdot\left(\frac{p_{1}+p_{2}}{z}\right)}{L}+\frac{12.1 \cdot d^{\mathrm{s}}}{L} \times \frac{1+192 \cdot d \cdot\left(\frac{p_{1}+p_{2}}{z}\right)}{1+237 \cdot d \cdot\left(\frac{p_{1}+p_{2}}{z}\right)}$ liter $/$ second,

where $d$ is the inside tubing diameter (centimeter), $L$ is the pipe length (centimeter), $L \geq 10 \times d, p_{1}$ is the upstream pressure (millibar), and $p_{2}$ is the downstream pressure (millibar). 


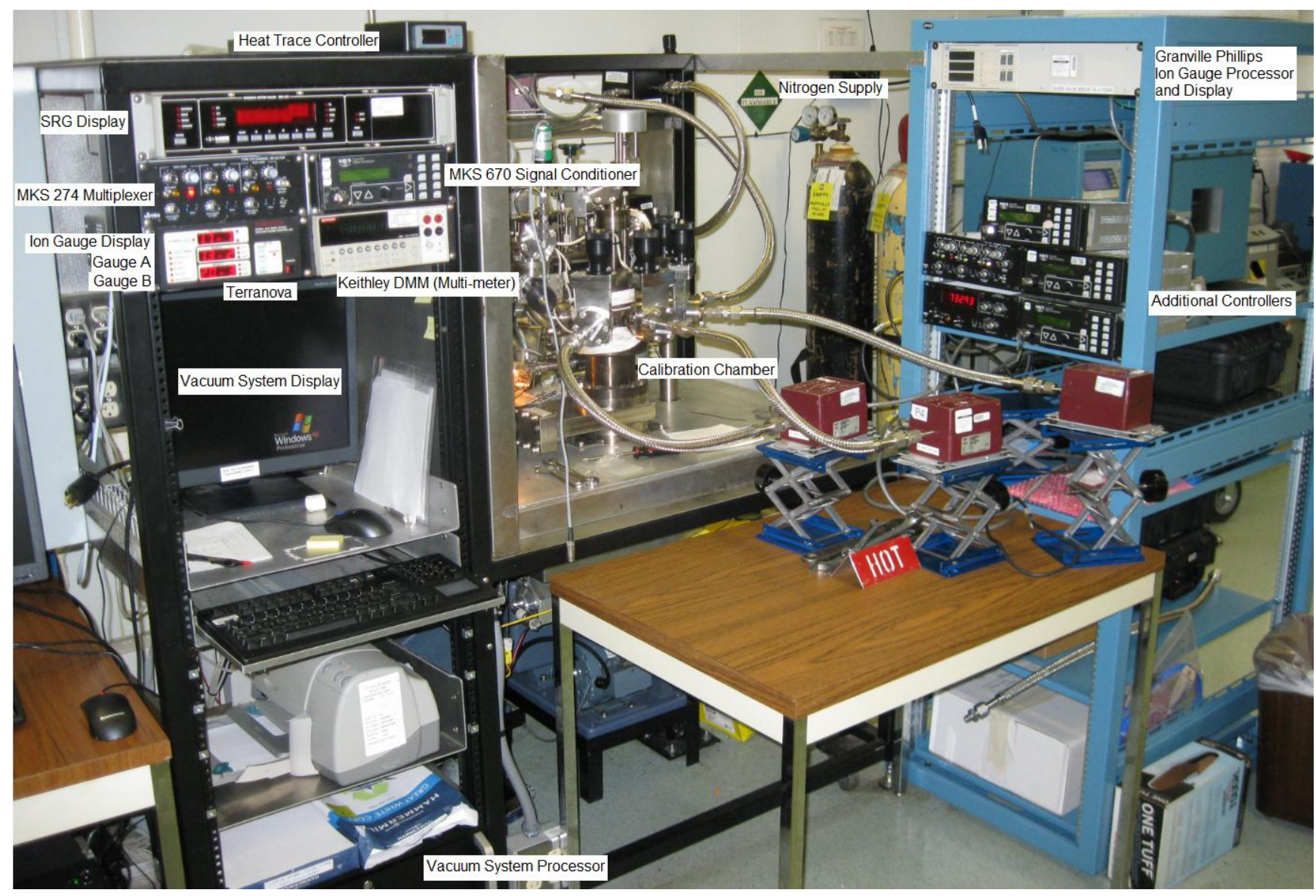

Figure 2. Vacuum system and controllers.

\section{SYSTEM DESCRIPTION}

The system used for calibrations and testing was an Automated Vacuum Gauge Calibrator, VGMS-101, which was manufactured by Vacuum Technology, Inc. (VTI). The general layout of the system is shown in Fig. 2. The calibration chamber was a five liter stainless steel tank with attached nozzles for vacuum gauge connections. Figure 3 provides a process and instrumentation drawing of the system as a basis for discussion, where most of the connecting tubing between components is $1 / 8$ inch ( 0.32 centimeter) stainless steel, and nozzle connections to the calibration chamber are 1-3/8 inches ( 3.49 centimeter) stainless steel tubing.

To initially evacuate the chamber, the roughing pump, M3, is used. Then, to maintain the calibration chamber at high vacuum, valves are opened between the gas feed tank, the calibration chamber and two operating vacuum pumps, i.e., the foreline pump, M1, and the turbomolecular (turbo) pump, M2. 


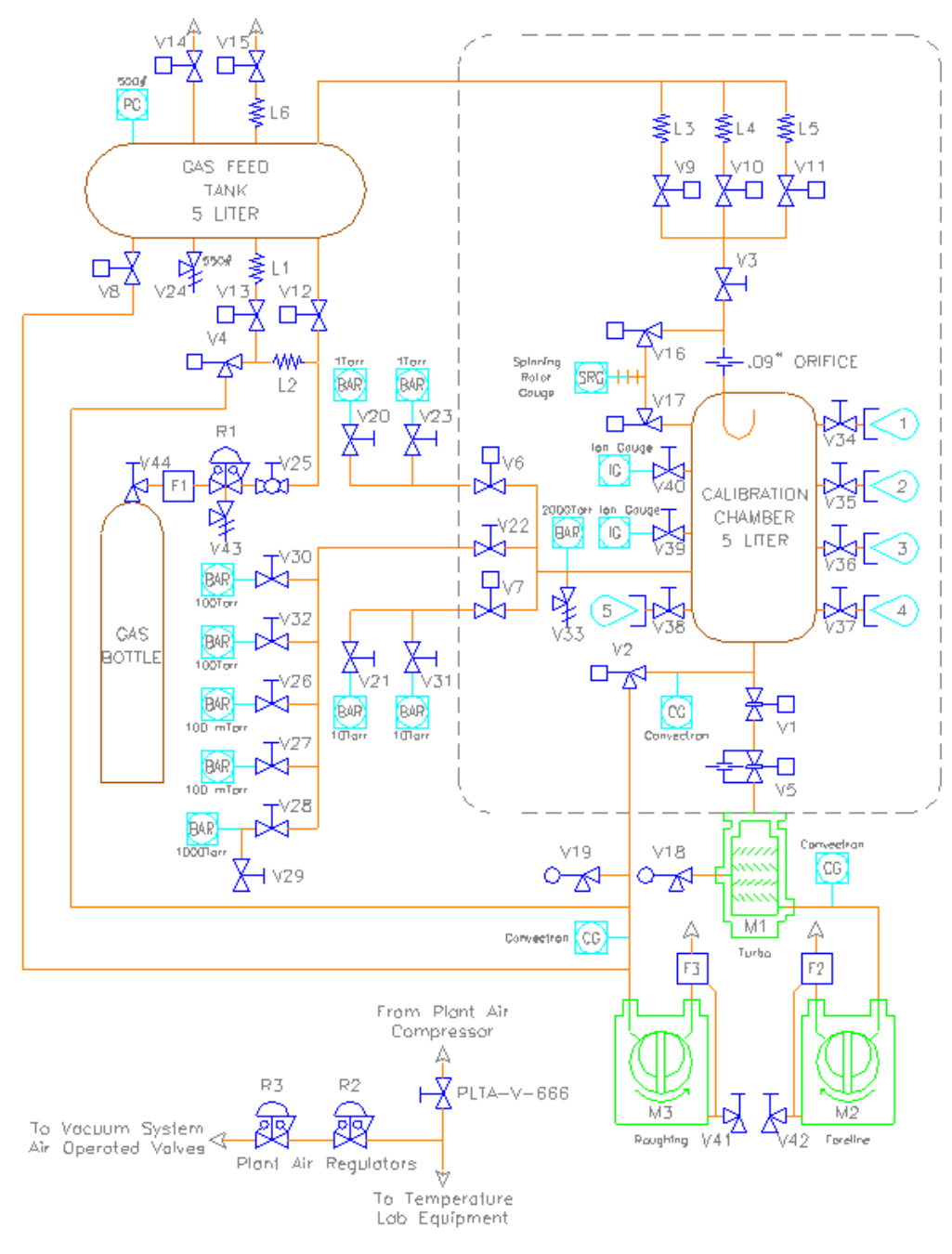

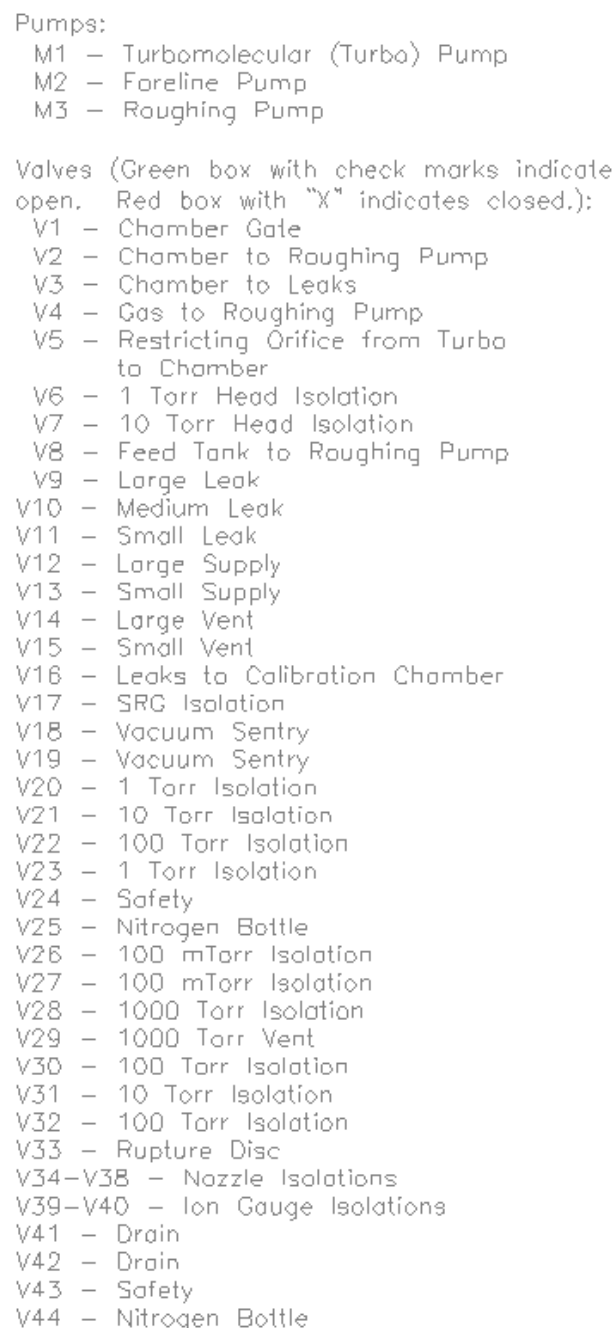

Figure 3. Vacuum system process and instrumentation drawing / Computer interface (Reprinted by permission of Vacuum Technology Incorporated, Oak Ridge, Tennessee).

\subsection{Calibrations}

Calibrations can be performed in automatic mode to obtain pressures at many set points, or calibrations may be performed manually to select each set point. Manual calibrations will be discussed here, where most of the data for this testing was collected using manual calibration techniques. For manual calibrations, valves and pumps are selected and operated one at a time as required, using a computer screen interface that is comparable to Fig. 3. For the calibrations performed during this research, the vacuum system is allowed to settle, or equilibrate for six minutes prior to the first calibration of a series of measurements, and the system is then allowed to settle for two minutes after each additional selected set point pressure is reached until all 
calibrations are completed. This settling time minimizes transient effects for all calibrations. Also, measurements were typically averaged over 30 seconds for each calibration, but 10 second averages were considered to determine the effects of averaging on measurement errors. These times were selected using multiple trial and error calibrations to minimize calibration errors. Measurements are typically obtained during a sequence of ascending or descending pressures, referred to simply as increasing or decreasing pressures in subsequent figures.

For an initial comparison of different gauge designs, measurements were performed at $1 \times 10^{-4}$ Torr, where the pressure ranges overlapped for each of the gauge designs under consideration. These simultaneous calibrations were performed for all of the gauges, and each gauge was found to be within its expected uncertainty, where the maximum uncertainties equaled $U_{C C G}=0.73 \%$, $U_{S R G}=3.64 \%, U_{C D G}=12.33 \%, U_{I G}=6.22 \%$ (See also Table 3). For this particular set of cross checks, the vacuum system was at equilibrium for weeks prior to calibrations, where valves were not operated for the purpose of preventing fluid transients.

\begin{tabular}{|c|c|c|c|c|c|c|c|}
\hline SRG, Torr & $\begin{array}{l}\text { SRG, } \\
\text { Maximum } \\
\text { Uncertainty }\end{array}$ & IG, Torr & \multicolumn{1}{|l|}{$\begin{array}{c}\text { IG, } \\
\text { Maximum } \\
\text { Uncertainty }\end{array}$} & & $\begin{array}{c}\text { CDG, Torr } \\
\text { CDG, } \\
\text { Maximum } \\
\text { Uncertainty }\end{array}$ & $\begin{array}{c}\text { Error, IG } \\
\text { to CDG }\end{array}$ & $\begin{array}{c}\text { Error, } \\
\text { SRG to } \\
\text { CDG }\end{array}$ \\
\hline $1.106 \mathrm{E}-04$ & $3.64 \%$ & $1.108 \mathrm{E}-04$ & $6.22 \%$ & $1.105 \mathrm{E}-04$ & $12.33 \%$ & $0.27 \%$ & $0.088 \%$ \\
\hline $4.29 \mathrm{E}-04$ & $3.64 \%$ & $4.767 \mathrm{E}-04$ & --- & $4.319 \mathrm{E}-04$ & $3.37 \%$ & $10.37 \%$ & $-0.46 \%$ \\
\hline $1.106 \mathrm{E}-04$ & $3.64 \%$ & $1.108 \mathrm{E}-04$ & $6.22 \%$ & $1.042 \mathrm{E}-04$ & $12.33 \%$ & $6.33 \%$ & $5.78 \%$ \\
\hline $4.299 \mathrm{E}-04$ & $3.64 \%$ & $4.769 \mathrm{E}-04$ & --- & $4.231 \mathrm{E}-04$ & $3.37 \%$ & $12.72 \%$ & $1.59 \%$ \\
\hline
\end{tabular}

Table 3. Cross checks of gauge operations.

\subsection{Gas Flow From the Feed Tank to the Chamber}

Referring to Fig. 3, the gas feed tank provides nitrogen to the chamber during calibrations. To do so, pressure is controlled in the feed tank using valve V8 to provide suction and valve V13 to provide pressurized nitrogen from the gas bottle, or tank. Gas travels at sub-sonic velocity to the leaks at valves V10 and V11, which are selected for different flow control. Installed in the tubing, leaks are cylinders with small diameter bores that permit flow to pass at specific flow rates. Since pressure ratios greater than $\approx 0.53$ across an orifice result in sonic flows [12], choked flow will occur inside the leaks. Nitrogen will flow through the leaks at 349 meter/second at $20^{\circ}$ $\mathrm{C}$, which is within the controlled temperatures range of the Vacuum Lab at SRSL. The geometry of the selected leak inherently results in a supersonic flow downstream of that leak, and a standing shock occurs downstream of the leak. Downstream of the shock, flow returns to a subsonic velocity before entering the chamber. 


\subsection{Gas Flow From the Chamber Through the Pumps}

Referring again to Fig. 3, valves V1 and V5 are opened to the turbo and foreline pumps during calibrations to withdraw nitrogen from the chamber. The turbo pump operates similar to a jet turbine and is capable of producing higher vacuum than the foreline pump. The continuous duty foreline pump and start-up roughing pumps are of identical design, where they both contain oil reservoirs to trap contaminants.

\subsection{Types of Gauges}

Several types of gauge designs were considered with respect to fluid transients and are briefly discussed here. For the various gauges that were tested, fluid transient anomalies were only observed at very low pressures approaching $1 \times 10^{-8}$ Torr. This observation was critical to conclusions with respect to molecular flow, where transient effects only occurred due to sudden pressure drops down to low pressures. Accordingly, various gauges are considered here.

Also of note, several gauges were used as standards to perform calibrations. The uncertainties for each of these standards were traceable to primary standards that are maintained by national laboratories, such as NIST. Primary standards are maintained by national laboratories to ensure that uncertainties are precisely known through comparison. This traceability ensures the accuracy of standards that were used by Savannah River Standards Laboratory during this testing.

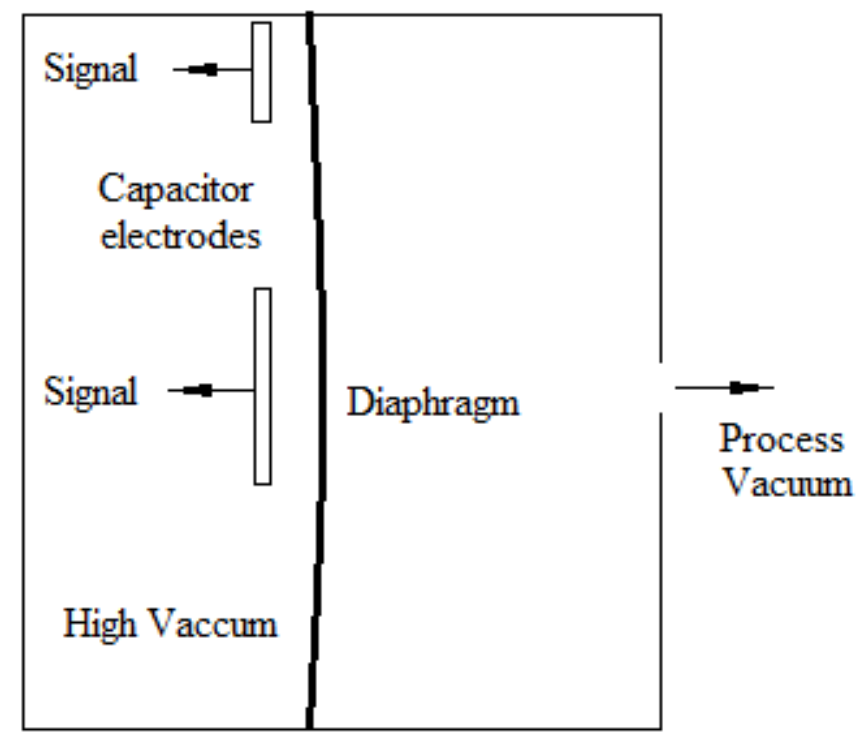

Figure 4. CDG operation [13] (๔ 1998 Putnam Media Inc. and Omega Engineering, Inc. Reproduced with permission of omega Engineering, Inc. www.omega.com). 


\section{CAPACITANCE DIAPHRAGM GAUGES}

Capacitance diaphragm gauges measure the change in capacitance that occurs when a vacuum deflects an Inconel diaphragm to induce a measurable change in capacitance, as shown in Fig. 4. CDGs used as SRSL standards are MKS instruments, Model 690, Baratrons.

Hysteresis occurs in some instruments when mechanical components are stressed, where their mechanical properties differ as the stress is relieved. That is, in some pressure instruments, the measured pressures differ when increasing or decreasing the applied pressures. In general, CDGs are considered to have negligible hysteresis effects.

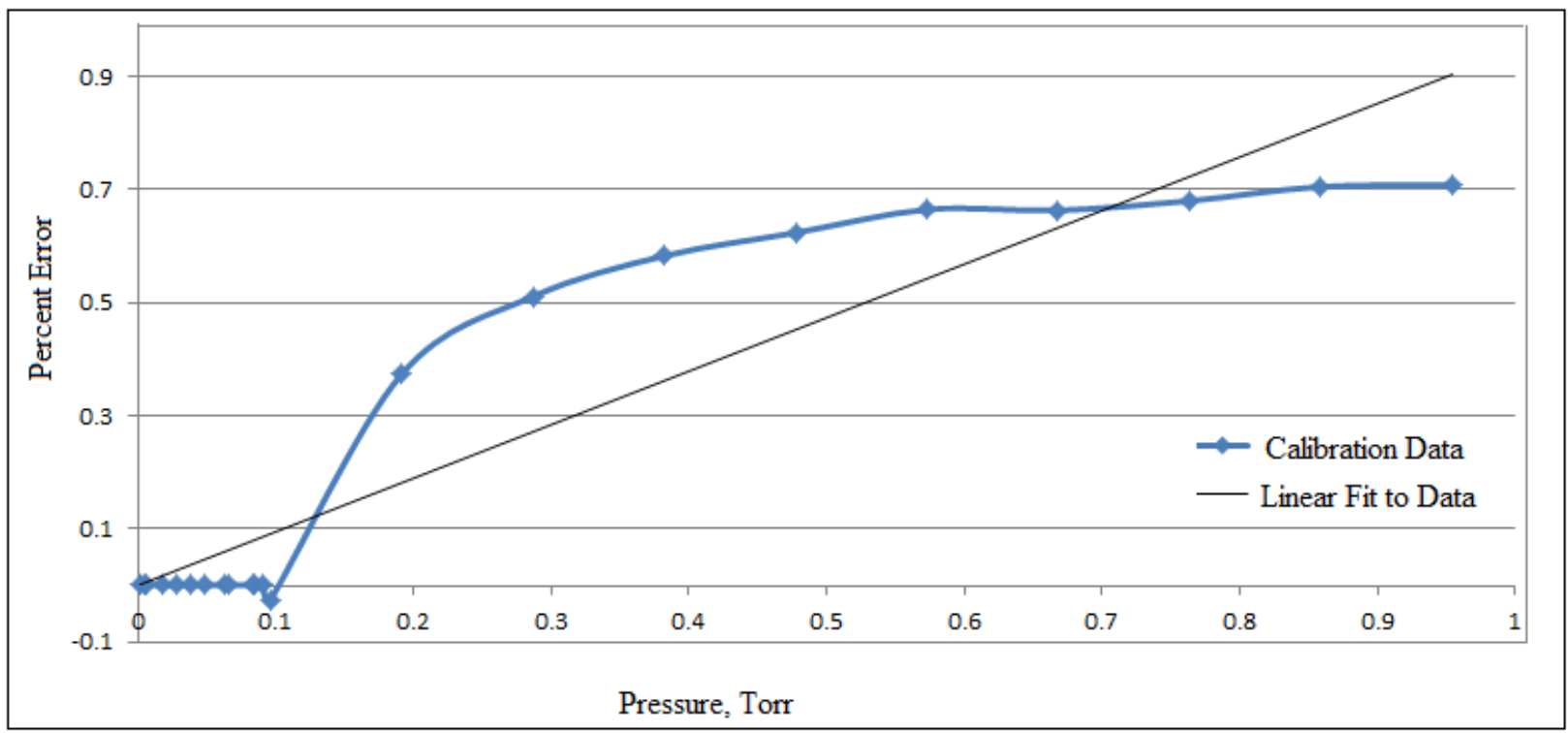

Figure 5. Typical CDG calibration data (1 Torr gauge shown, M\&TE number: 20.2053-PE-C).

\subsection{CDG Calibrations Without Transients}

Actual values for pressures were determined as discussed in the derivation of Eq. (1). Errors associated with a CDG calibration are shown in Fig. 5 This figure is representative of a series of tests performed at SRSL to improve accuracy at the lower range of CDG's. th system was at equilibrium for days before testing started to ensure that transient effects were minimized. To collect data, settling times to obtain the first set point were typically $5-20$ minutes to again ensure that transient effects were minimized. Note that percent errors are less than one percent after transient effects were minimized. That is, the conditions for this set of calibrations were near equilibrium, but pressure adjustments were made to the system to obtain set points. This 
condition will be referred to in this research as a pre-transient condition as opposed to the definition of a transient, where a sudden pressure drop occurs.

\subsection{CDG Calibrations With Transients}

However, most CDG calibrations were subject to sudden pressure drops during the performance of calibrations, where pressures are dropped through the range of the DGD at the start of a calibration. For example, a 0.1 Torr (100 millitorr) Baratron CDG was used for this investigation (M\&TE number: SL-457K). The installed CDG was used as a cross check to validate gauge operations when compared to an IG and and SRG, where the different gauge design pressures overlapped for a small range of pressures (near $1 \times 10^{-4}$ Torr). As shown in Table 3, all gauges were within the specified uncertainties. Pressures were raised, lowered, and raised again during this test to confirm gauge performances.

Hundreds of CDG calibrations have been within calculated uncertainties for years at SRSL, where pressures were suddenly lowered during calibrations. These calibrations were typically performed using automatic mode calibrations, two to three minute settling times, and 30 second samples, which followed pressure drops through the vacuum gauge ranges. For example, in one test the percent error was $-6.3 \%$ at $1 \times 10^{-4}$ Torr (Fig. 6), where pressure measurements were considered to be minimally affected by sudden pressure drops for SRSL calibrations (Table 5, M\&TE number: SL-457I calibrated with SL-457T). That is, the percent error was within the expected uncertainty within two minutes following pressure transients. Note that signs $( \pm)$ are added to calculated uncertainties $( \pm U)$, and that the magnitude of the uncertainty, $|U|$, is independent of the sign of the percent error (See Equation 6).

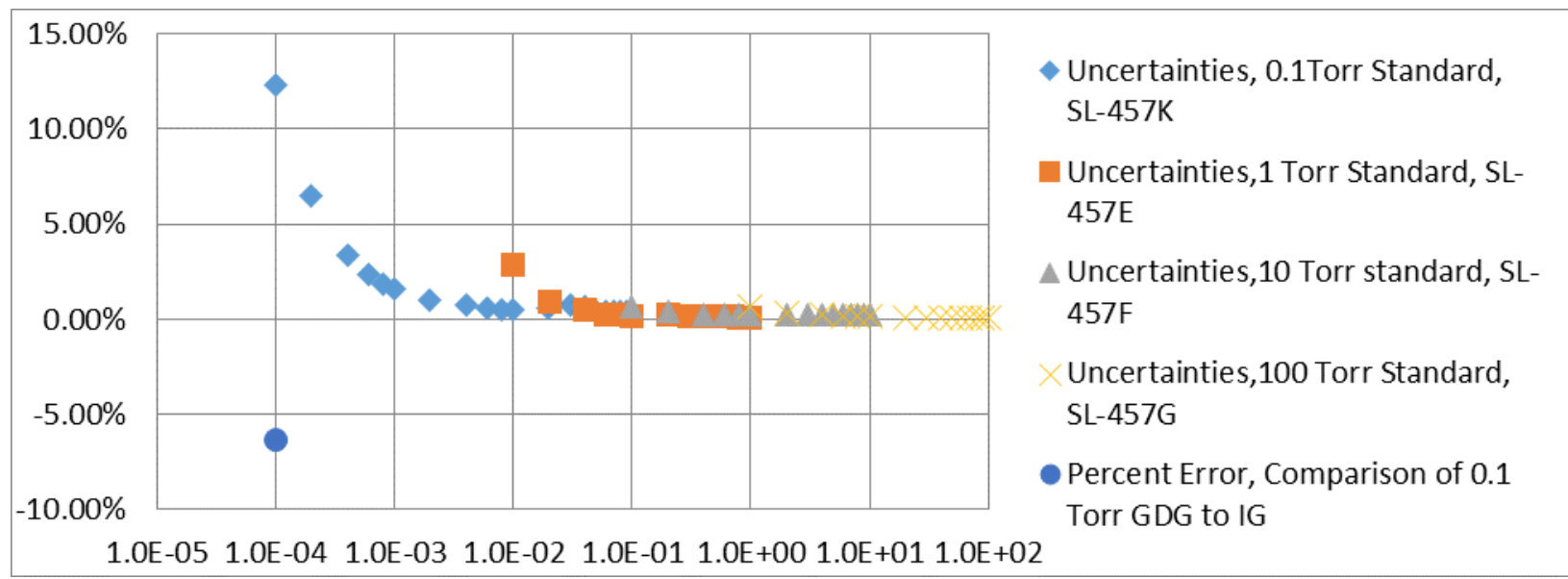

Figure 6. CDG Uncertainties, $\left|U_{R E F}\right|$

Typical CDG uncertainties provided by PSL are shown in Fig. 6 for 0.1 Torr, 1 Torr, 10 Torr, and 100 Torr gauges, where PSL used a vacuum system similar to the SRSL vacuum system for 
calibrations. Note that uncertainties increased at lower pressures. CDG's with different ranges are built the same, and uncertainties were expected to be consistent for CDG's with different pressure ranges. PSL calibrations were consistent with SRSL calibration results. Consequently, the increasing errors at lower pressures are probably caused by sudden pressure drops during calibrations, but this issue was not investigated thoroughly for CDG's. Longer settling times may have resulted in less error, but the errors were acceptable since they were within the specified uncertainties at time of test for the gauges of concern at SRSL. Observed errors were considered to be minor for SRSL purposes, but the noted 12.3\% maximum error shown in Fig. 6 may be significant to other vacuum system users, where transient effects were noted up to about $1 \times 10^{-2}$ Torr.

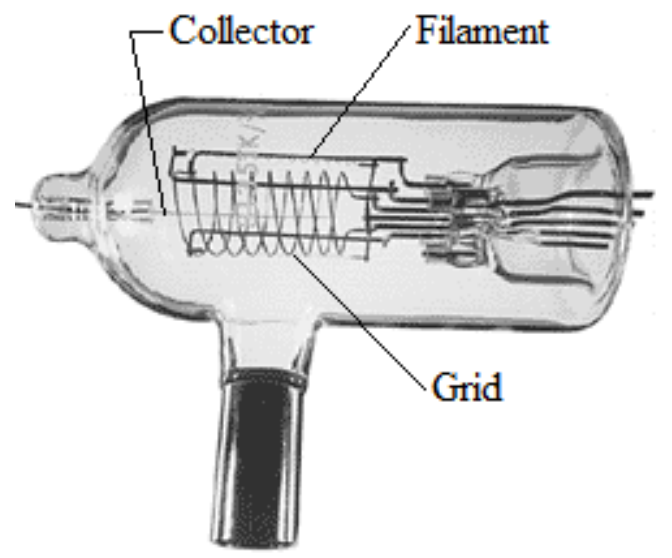

Figure 7. Glass tube ion gauge [14] (Adapted by permission of Scientific Instrument Services http://www.sisweb.com/vacuum/sis/inlinga.htm).

\section{ION GAUGES}

Ionization gauges, (ion gauges) are available in several designs. For the system used in this research a glass tube ion gauge similar to Fig. 7 was used for system control, and two metal case ion gauges were used for calibrations at SRSL. The installed glass gauge was typically observed to be in error by a factor of two or more, and accordingly was not evaluated in detail for this study. The accurate metal case ion gauges were Granville Phillips, Model 370, ion gauges (M\&TE numbers: SL-457U and SL-457T).

In an ion gauge, a glowing, negatively charged filament is heated using a 280 Volt potential to cause a cloud of electrons to be attracted to a spiraling grid and cylindrical collector. The positively charged grid acts to increase the number of ionizations and magnify the signal output of the gauge. Electrons pass the grid to the positively charged collector to induce an electric current, which is proportional to the pressure in the gauge. The gauge controller then processes the current signal to display a vacuum reading. 


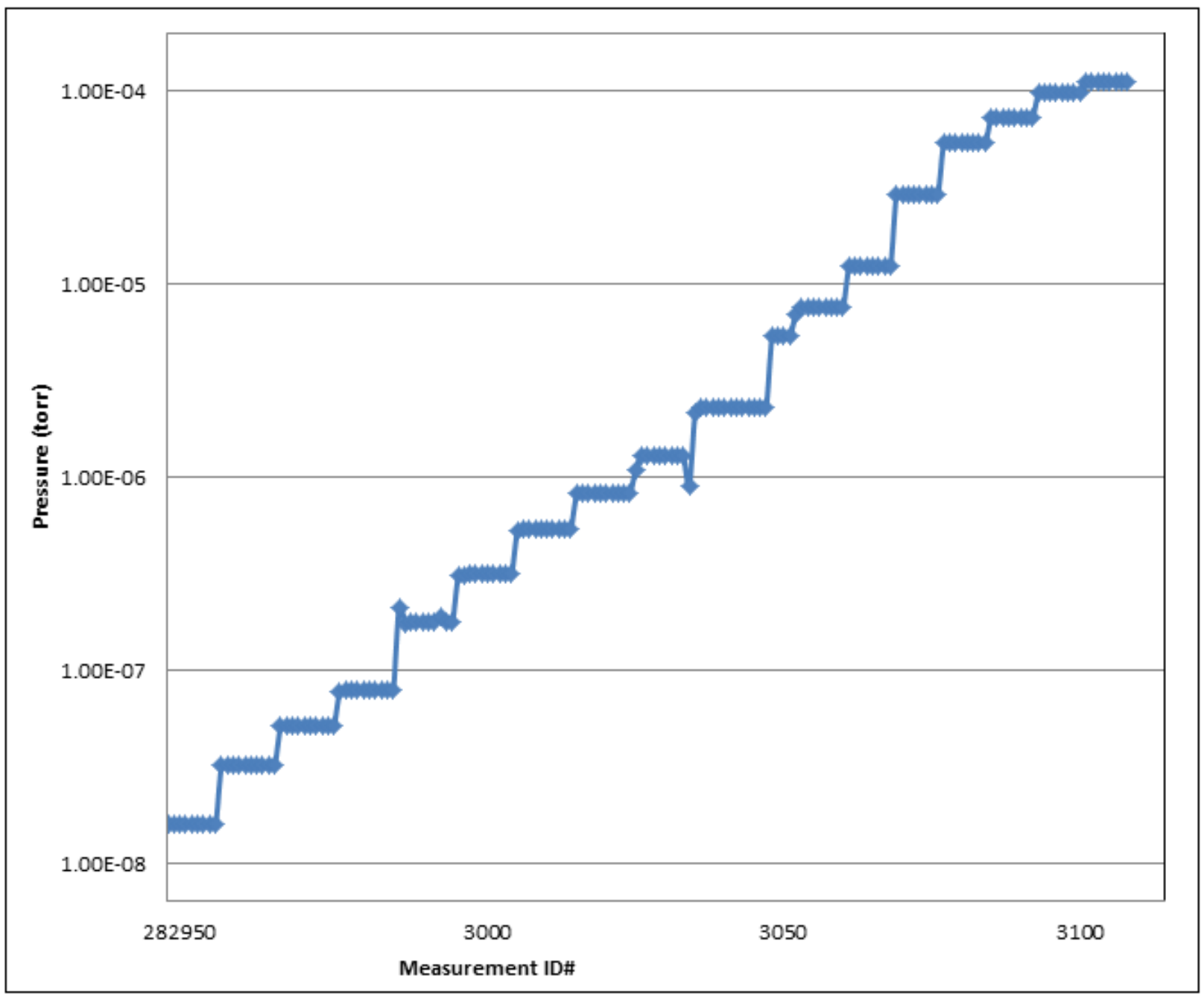

Figure 8. Typical PSL calibration data for an ion gauge (M\&TE number: SL-457U) (PSL data provided by Jay Bennett).

\subsection{IG Calibrations}

IG calibrations are performed at PSL for SRSL, where typical collected data are shown in Fig. 8. PSL provided calibration reports specifying the total uncertainty for each pressure that was measured. Note that pressures are measured while the chamber pressure was increased. Actual pressures were determined at SRSL from these gauges in accordance with Eq. (2). 


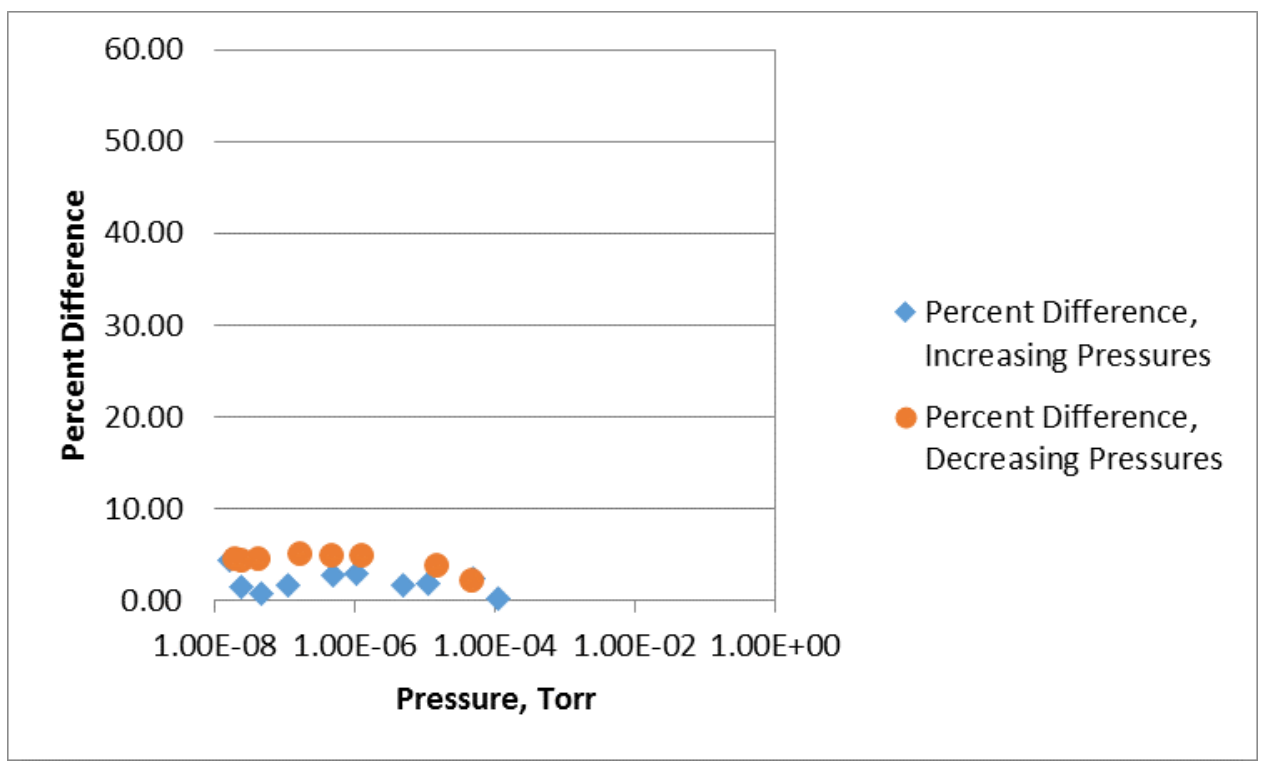

Figure 9. Comparison for one IG to a second IG, percent of reading errors following startup and prior to a sudden pressure drop applied to the system (Calibration of SL-457T with a SL-457U standard).

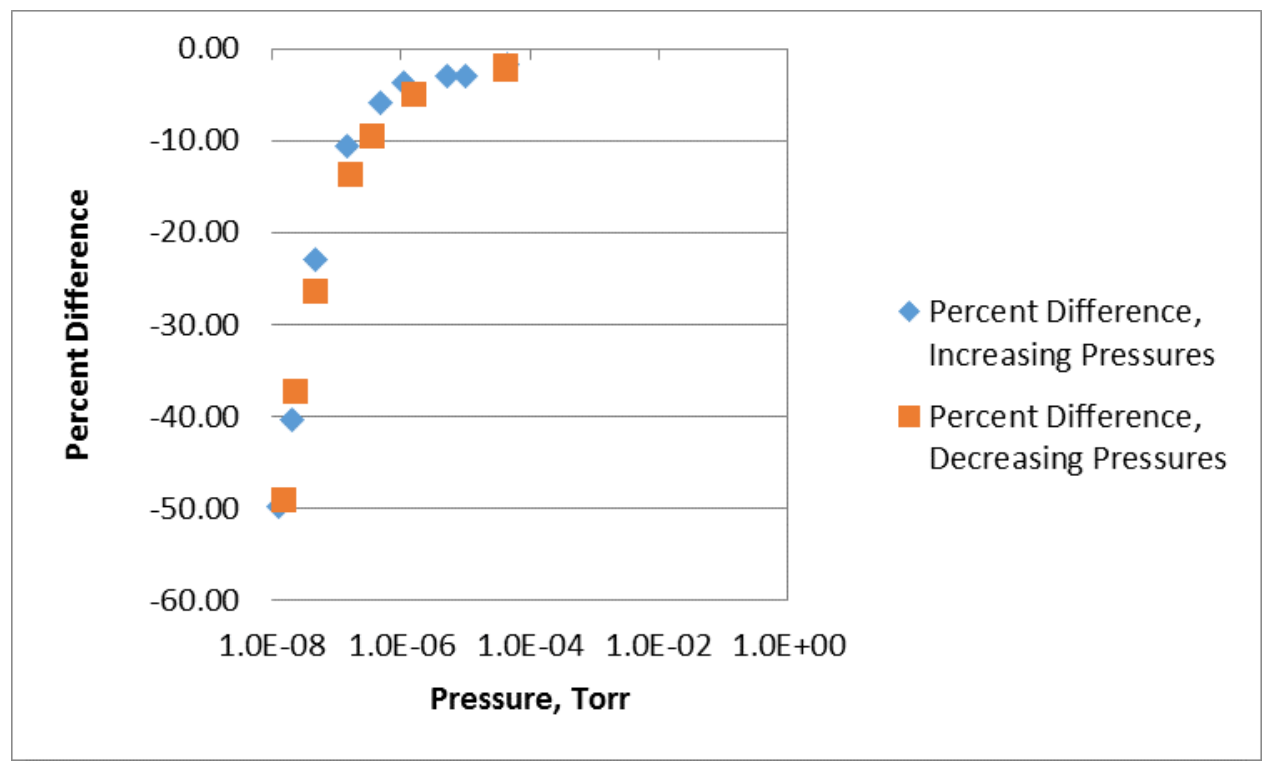

Figure 10. IG percent differences after a sudden pressure drop was applied to the system, 30 second samples (Calibration of SL-457T using SL-457U standard).

\subsection{IG Test Results}

When calibrations were performed after the system was idle for a week or so, the measured pressures were well within uncertainties as shown in Fig. 9. For one gauge, equilibrium was not reached for several days. In other words, calibrations may typically be performed after the system has reached equilibrium for about a week. Also, when this particular system is started up 
from a shutdown, a one week, or so, delay was usually required to obtain minimum pressures as the system outgassed, and moisture contaminants evaporated from internal surfaces. This delay was required to ensure that outgassing did not affect test results. Once the system is outgassed, it remains in continuous operation. For the research performed here, final testing was performed after several weeks of system operation at its lowest operating pressure. Shorter start-up times may affect low pressure measurements.

After initial calibrations were performed, pressures were suddenly lowered from $1 \times 10^{-4}$ Torr to $\approx 1 \times 10^{-8}$ Torr, and the percent difference between gauge readings on two separate ion gauges significantly exceeded the total uncertainty, $U$, as shown in Fig. 10, where data was obtained from Table 1. Note also that these percent differences were measured using two gauges of the same design, which indicated that pressure measurement disparities for identical gauges varied due to differences in molecular flow patterns. These results were consistent throughout multiple tests, and on occasion the uncertainty was $-80 \%$ following a pressure drop, where a $-49 \%$ uncertainty is shown in Fig. 10. Percent differences were similar later the same day during a test that followed the test shown in Fig. 10. That is, percent differences varied significantly from test to test and from gauge to gauge for similar test conditions. These percent differences represented actual measured pressures inside the gauges, where measured pressures were consistently lower than system pressures when the pressure was suddenly lowered. There is no doubt that sudden pressure drops in systems affect pressure readings for ion gauges.

Even so, the magnitudes of pressure drops required to significantly affect pressure readings were not fully investigated, but pressure differences were noted for pressure drops as small as an order of magnitude in pressure. Note also, that percent differences (percent errors for readings) were not significant until pressures dropped below $5 \times 10^{-6}$ Torr for ion gauges. If sudden pressure drops occur in any given system, the gauge user should evaluate the uncertainty effects if gauge accuracy is important.

\section{COLD CATHODE GAUGES}

Many years of seemingly random CCG calibration failures at SRSL prompted this investigation. SRSL performed procedures correctly, and calibration standards were traceable to national standards, but gauges continued to fail calibrations. For years, contamination was considered to be the sole cause of gauge calibration failures. Corrosion and saturation of electrodes have been reported by vendors as possible sources of measurement errors at low pressures following storage at atmospheric conditions, and corrosion has been evidenced during calibrations at SRSL. This study discovered an additional cause of incorrect vacuum gauge readings for cold cathode gauges, where sudden drops in pressure resulted in significant gauge errors as the major contributor to many SRSL gauge calibration failures. This cause of incorrect gauge readings was previously unknown to manufacturers, national laboratories and vacuum system users. In fact, a literature review did not yield any research in this area of molecular flow fluid transients and vacuum gauge errors. 
Inside the cold cathode gauge, a combination of DC voltage and stationary magnets cause electrons to travel in long spiraling orbits. Moving electrons then ionize other electrons in the CCG to induce measurable voltages, which are converted to pressures by a processor. The basic components of a CCG are shown in Fig. 11. A Pfeiffer, PKR 251 cold cathode gauge was evaluated during this research (M\&TE number: 137-PE-F).

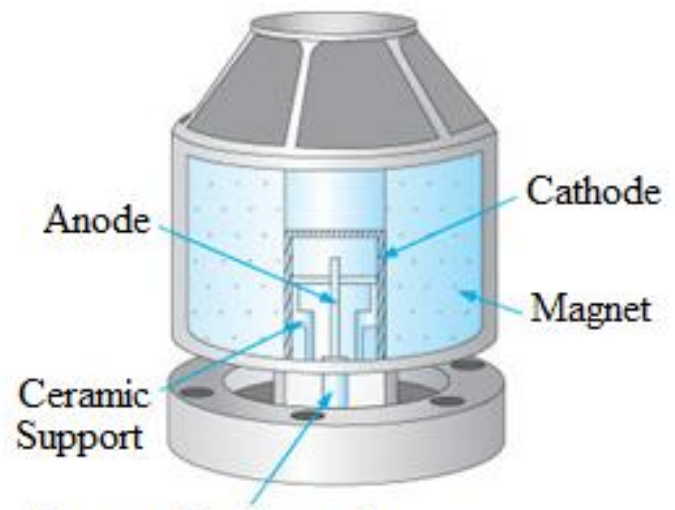

Vacuum Feedthrough

Figure 11. Typical cold cathode design, Lesker [15] (Reprinted by permission of Kurt J. Lesker Company).

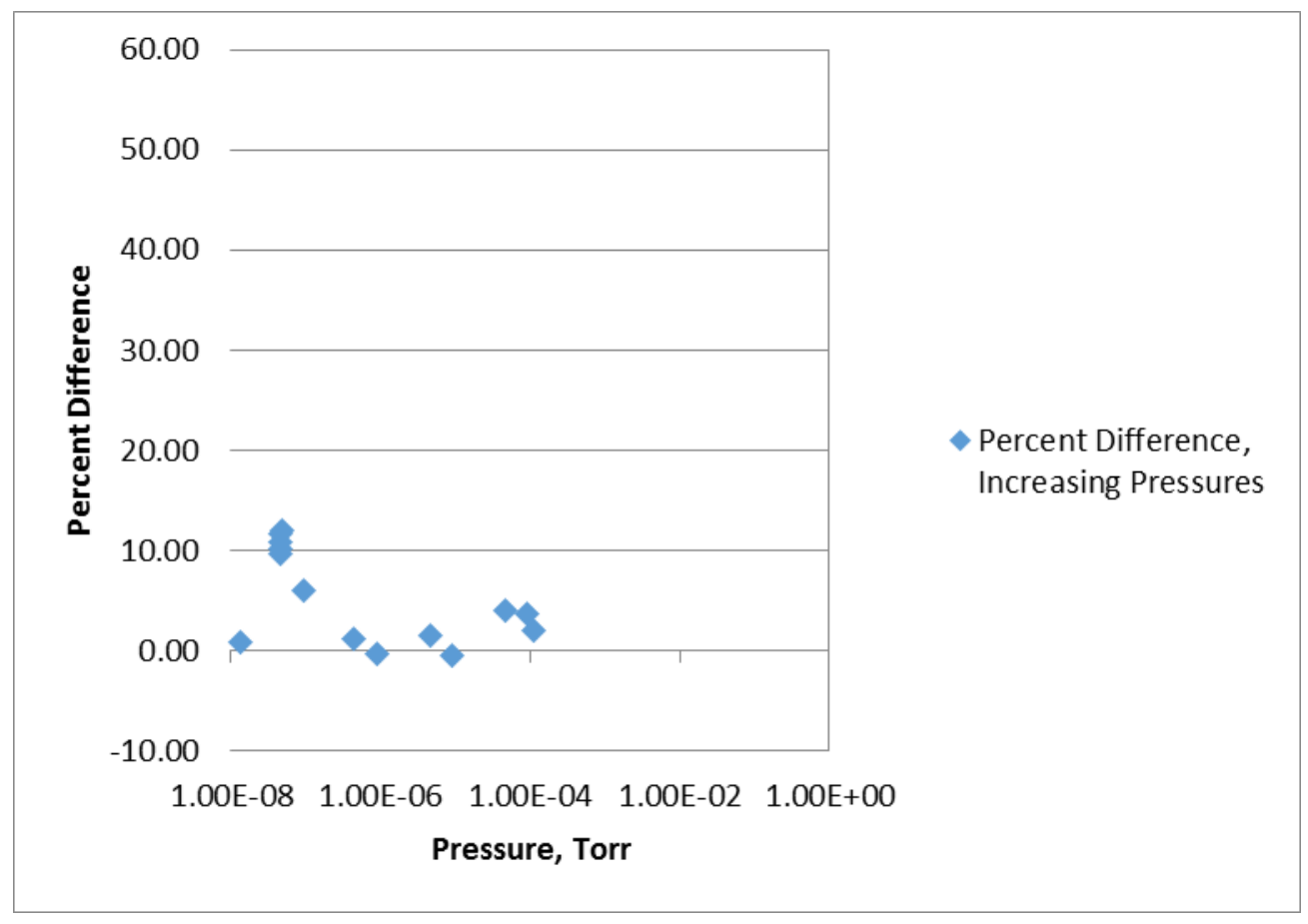

Figure 12. Comparison of measurement errors for a CCG prior to a system pressure drop (137PE-F, Calibrated using a SL-457U, IG standard). 


\subsection{CCG Calibrations}

When pressures are not suddenly lowered, reasonable errors between standards and CCG's may be obtained. The example shown in Fig. 12 compares an IG to a CCG for an increasing pressure calibration, where an IG was used as the laboratory standard for calibration performance.

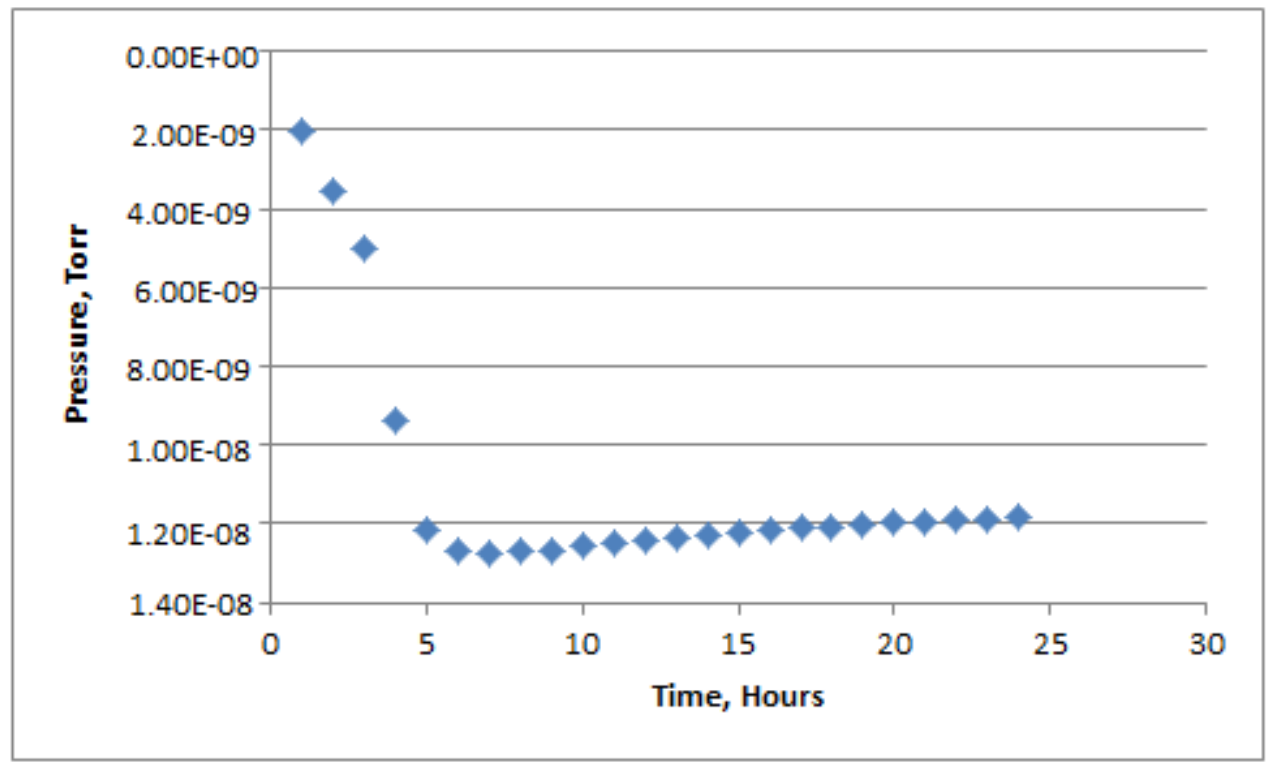

Figure 13. Gauge pressures following a pressure drop in a CCG (137-PE-F, Calibrated using a SL-457U, IG standard).

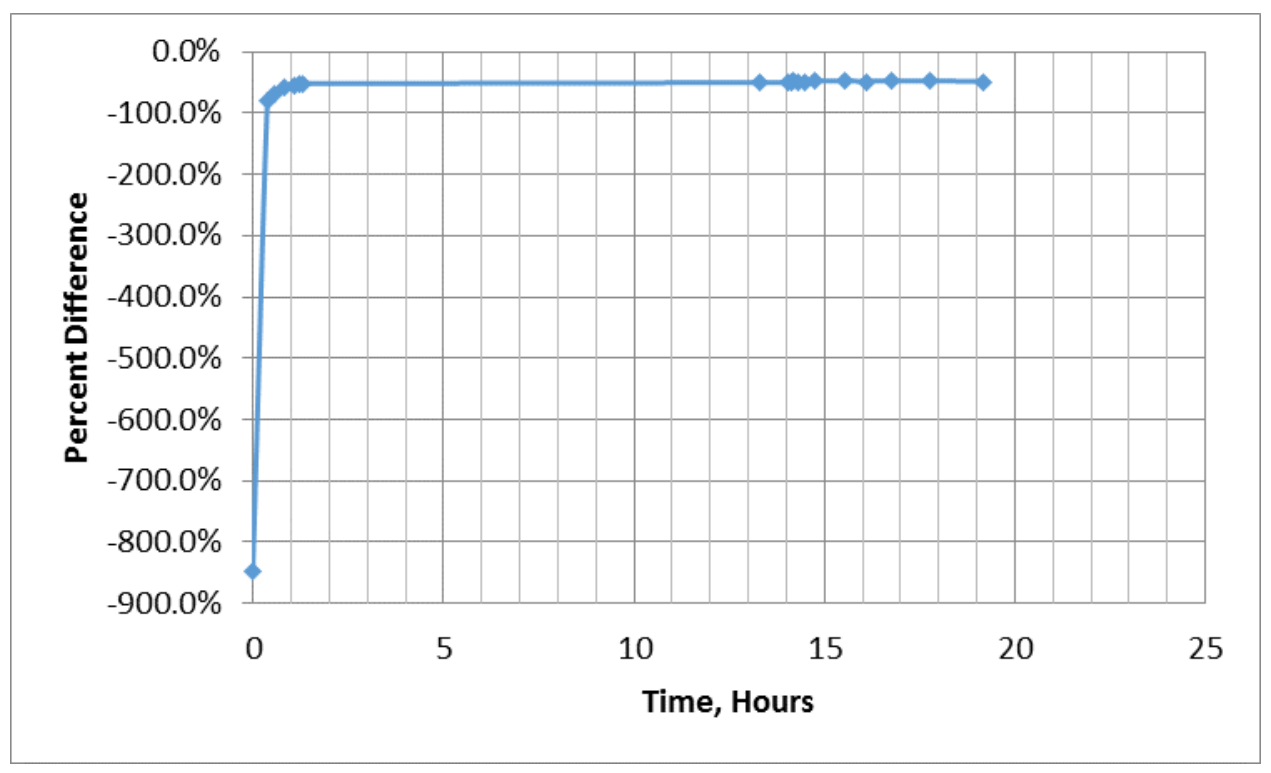

Figure 14. CCG performance following a pressure drop (137-PE-F, Calibrated using a SL-457U, IG standard). 


\subsection{CCG Test Results}

Typical test results for a CCG, subjected to a sudden pressure drop, are shown in Figs. 13 and 14, where a new CCG was compared to a laboratory standard IG. Constant uncertainties for CCGs were typically reached in three to five hours, following a sudden pressure drop. However, constant pressures were not obtained until more than a day passed, as shown in Fig. 14. Even so, note that errors are still significant (49.2\%) after a single day of gauge operation following a transient. During low pressure transients, CCG's have the highest uncertainties of the gauges considered. This fact is attributed to the complex flow path associated with the molecular flow entering the CCG for measurement, where CCG's have the most restrictive flow path of the gauges investigated.

\subsection{CCG Corrosion Effects}

Corrosion of CCG's during storage is also a significant problem. Figures 12 through 14 provide calibration data for a new, as purchased, gauge. However, Fig. 15 provides calibration data for another gauge that was calibrated after extended storage for approximately one year. Prior to this particular calibration, the CCG was installed for four days on the SRSL vacuum system to ensure that equilibrium was obtained in the vacuum system for the CCG. Subsequent gauge errors were attributed to corrosion due to storage on the shelf, where the gauge was subject to changing humidity. See Figs. 12 and 15 to compare data from a new gauge to a corroded gauge. The difference in errors due to storage is quite significant, where a new gauge had a maximum percent error of $12 \%$, and a corroded gauge had a maximum error of $122 \%$.

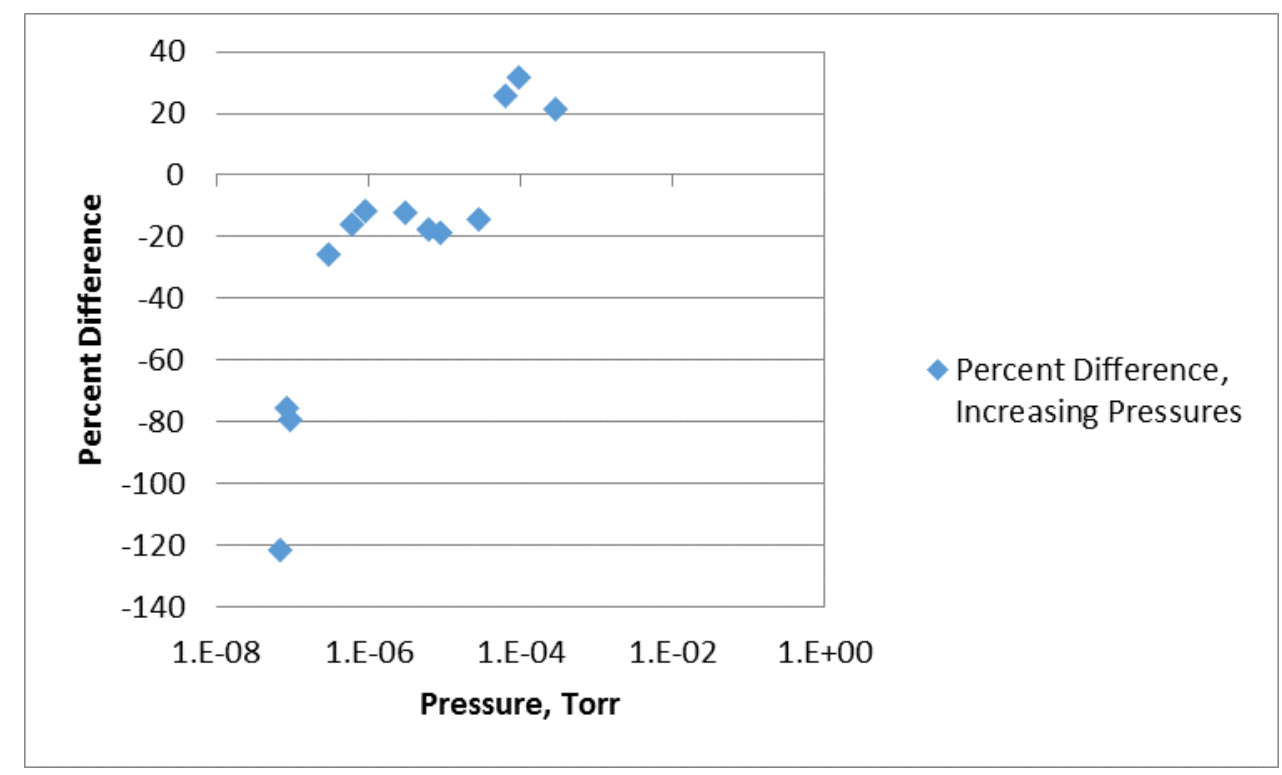

Figure 15: CCG Measurement errors following shelf storage (129-PE-K, Calibrated using a SL457U, IG standard). 
Corrosion effects were also noted during previous calibrations at SRSL for gauges that were subject to extended storage, where cleaning of gauges tended to lower gauge errors. Storage of gauges in atmospheric conditions provides a continuous source of moisture to accelerate corrosion. Corrosion effects were not investigated while gauges were installed at vacuum, but as installed corrosion effects on cold cathode gauges should be negligible due to extremely low moisture content in vacuum systems. Special storage precautions may reduce gauge corrosion during storage. For example, CCG's may be sealed, preferably at vacuum, with flanges or valves to minimize moisture entrance into gauges.

\section{SPINNING ROTOR GAUGES}

In spinning rotor gauges, drag is caused by gas molecules passing over a magnetically levitated, spinning steel sphere. A residual drag across the rotating sphere is measured, and this drag is used to establish the pressure in the system. An MKS Instruments, SRG-3CE, spinning rotor gauge was used for this research (M\&TE number: SL-456G). The entrance tubing to the SRG is longer and smaller in diameter than tubing connected to an IG.

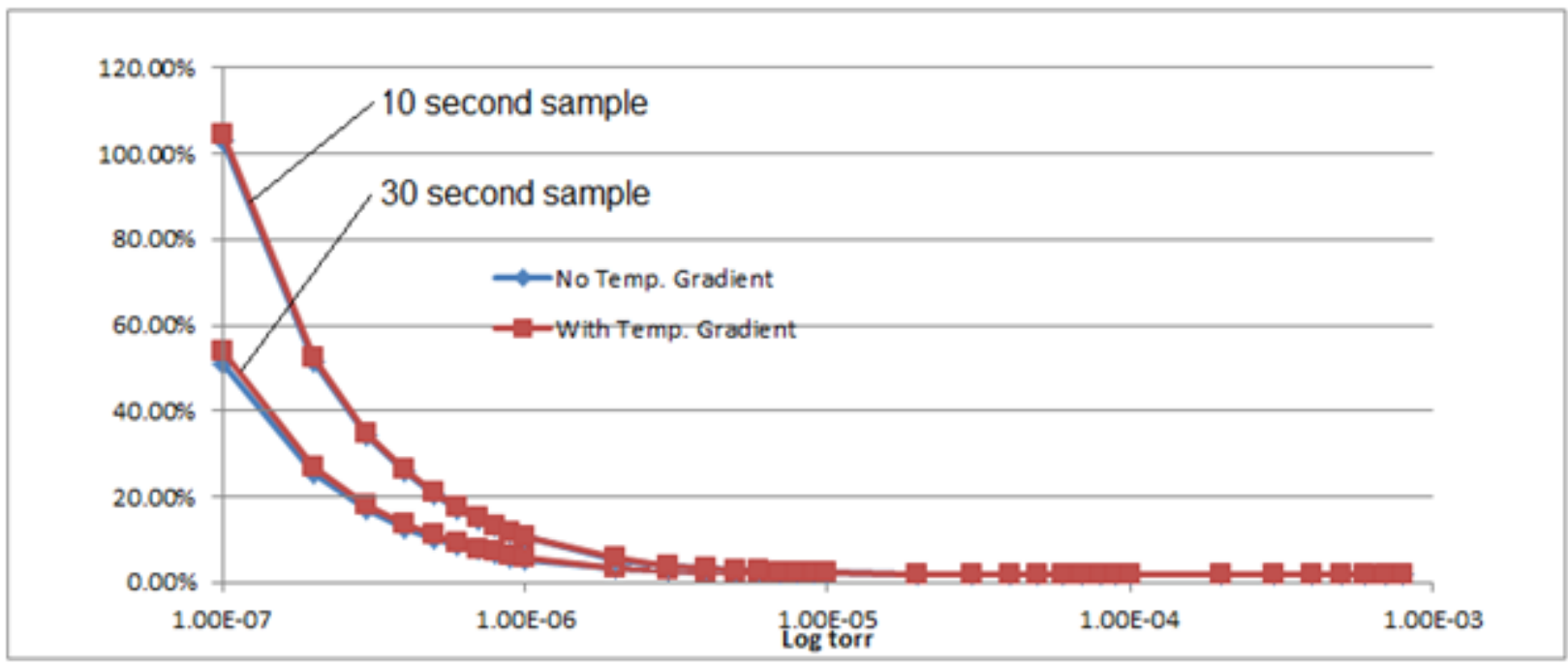

Figure 16. SRG uncertainties, $\left|U_{R E F}\right|$ (Calibration of SL-456G with a SL-457T, IG standard).

\subsection{SRG Calibrations}

SRG's are calibrated by NIST for SRSL where multiple measurements are performed at a single pressure, using a primary transition-range vacuum standard which generates a known pressure by transmitting a known flow rate through an orifice of known area. The NIST uncertainty at this pressure is augmented by Excel ${ }^{\circledR}$ spread sheets to calculate uncertainties throughout the applicable range, using an averaged value for the system zero pressure. There are several influences on the calculated system uncertainty, $u_{S Y S}$. 
NIST SRG uncertainties $\left(U_{R E F}\right)$ included the ball dimensions, material properties, ball rotor speed, rotor deceleration rate, and temperature, as provided by James Fedchak of NIST. The effects of these uncertainties are shown in Fig. 16, where $U_{R E F}=2.04 \%$ from NIST for the single point calibration value, and the SRSL total uncertainty $U=3.64 \%$. PSL has noted that there are uncertainties due to ball rotational effects as depicted in Fig. 17, which were considered in the NIST uncertainty analysis that was used to obtain Fig. 16 . That is, the $\approx 1 \%$ difference observed in Fig. 17 was included in the overall uncertainty for the SRG calibration.

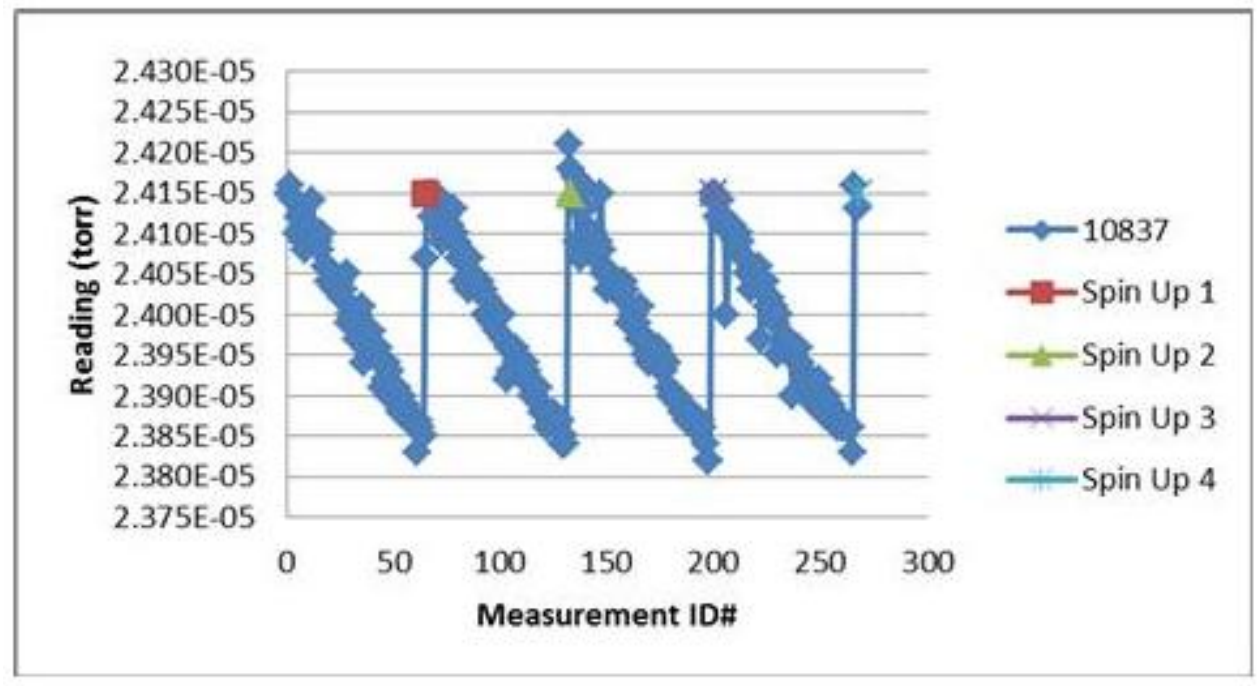

Figure 17. Ball rotation effects on an SRG (PSL data provided by Jay Bennett).

The uncertainty associated with the system zero influences the SRG uncertainty appreciably. To consider this effect typical uncertainty calculations are shown in Fig. 16, using both 10 and 30 second samples, where 30 second samples are recommended by the manufacturer. Measured pressures for 30 second samples are shown here, where a two minute settling time was permitted before the first data sample was obtained, and the 30 second sample averaged numerous high frequency data measurements provided by the SRG over 30 seconds. A 30 second sample time had a negligible effect on the zero value, where the uncertainty equaled $0.06 \%$ for the SRG data. For a 10 second sample time the uncertainty of the zero was $12.6 \%$. Referring to Fig. 16, the effect of this uncertainty for the zero value required for SRG measurements can be seen to nearly double the predicted uncertainty when 10 and 30 second sample results are compared. To condense these statements, a 30 second sample time minimizes uncertainties to reasonable calculated values, but a 10 second sample time adds unnecessary uncertainty to the calculation. In short, SRG's have a significant calculated uncertainty associated with the gauge. SRG use was not recommended for calibrations using the SRSL system at high vacuum, but at higher pressures the SRG provides a dependable instrument not subject to significant drift over time. 


\section{$9.2 \quad$ Typical SRG Measurements}

Not only were uncertainties predicted to be high at low pressures for the SRG, measurements showed that percent errors were even higher than predicted. Numerous tests with SRG's provided similar results, using two minute settling times and 30 second samples. Typical error results are shown in Fig. 18, where initial SRG tests were performed after the system was operated without pressure drops for two days to ensure equilibrium before testing. For this test, pressures were incrementally increased from approximately $1 \times 10^{-8}$ Torr to $10 \times 10^{-4}$ Torr, and then incrementally decreased back down to $1 \times 10^{-8}$ Torr, where the percent errors (percent differences) are shown in Fig. 18 for these increasing and decreasing pressure calibrations. Note that the predicted, linearized uncertainty for a 30 second sample equals $\approx 41.8 \%$ at $1.5 \times 10^{-7}$ Torr (Fig. 16), and the measured uncertainty equals $55.4 \%$ at $1.5 \times 10^{-7}$ (Fig. 18), such that the measured percent error exceeds the calculated uncertainty.

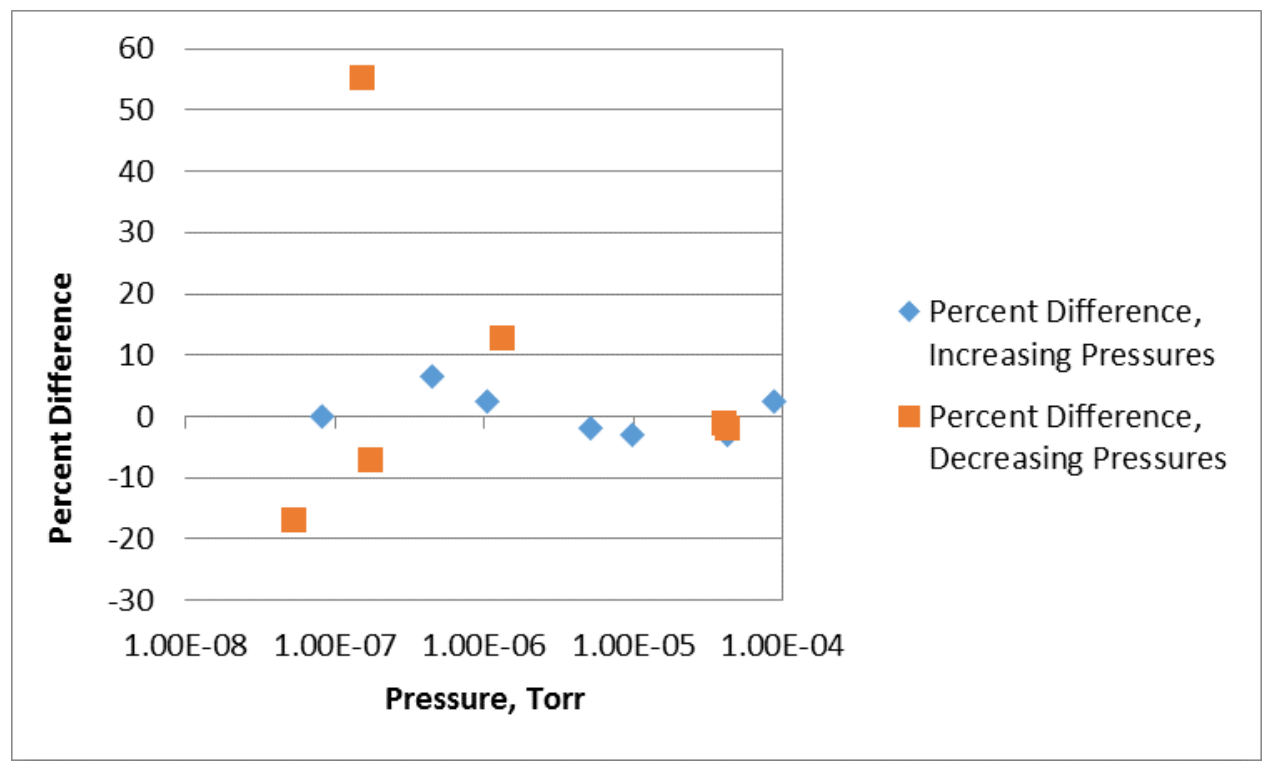

Figure 18. SRG performance for a pressure calibration before a sudden pressure drop was applied to the system, 30 second samples (Comparison of SL-457T to SL-456G standards).

\subsection{SRG Test Results}

When the pressure was suddenly lowered in the vacuum system, pressures were also measured in numerous tests, where Fig. 19 provides representative data. By comparing Figs. 18 and 19 , the errors were observed to significantly increase when the pressure was suddenly lowered from $\approx 1 \times 10^{-4}$ Torr to $\approx 1 \times 10^{-8}$ Torr. This observation concluded that sudden pressure changes significantly affected SRG performance at low pressures. Similar results were observed during numerous other tests. Higher uncertainties during pressure transients for the SRG are attributed to the fact that the entrance tubing from the vacuum chamber to the SRG is longer and of smaller diameter than the entrance tubing to the ion gauge. That is, the molecular flow has a 
more difficult and restrictive path to enter the SRG than it does to enter the IG. Shorter tubing may minimize transient errors, but was not investigated.

All in all, SRG uncertainties were quite excessive at high vacuum. With respect to this study, measured errors are consistent from test to test, where marked differences between both normal system performance and performance following a sudden pressure drop clearly demonstrated the effects of fluid transients on SRG's. In short, SRG's had high uncertainties for all conditions when operating pressures were below about $5 \times 10^{-6}$ Torr.

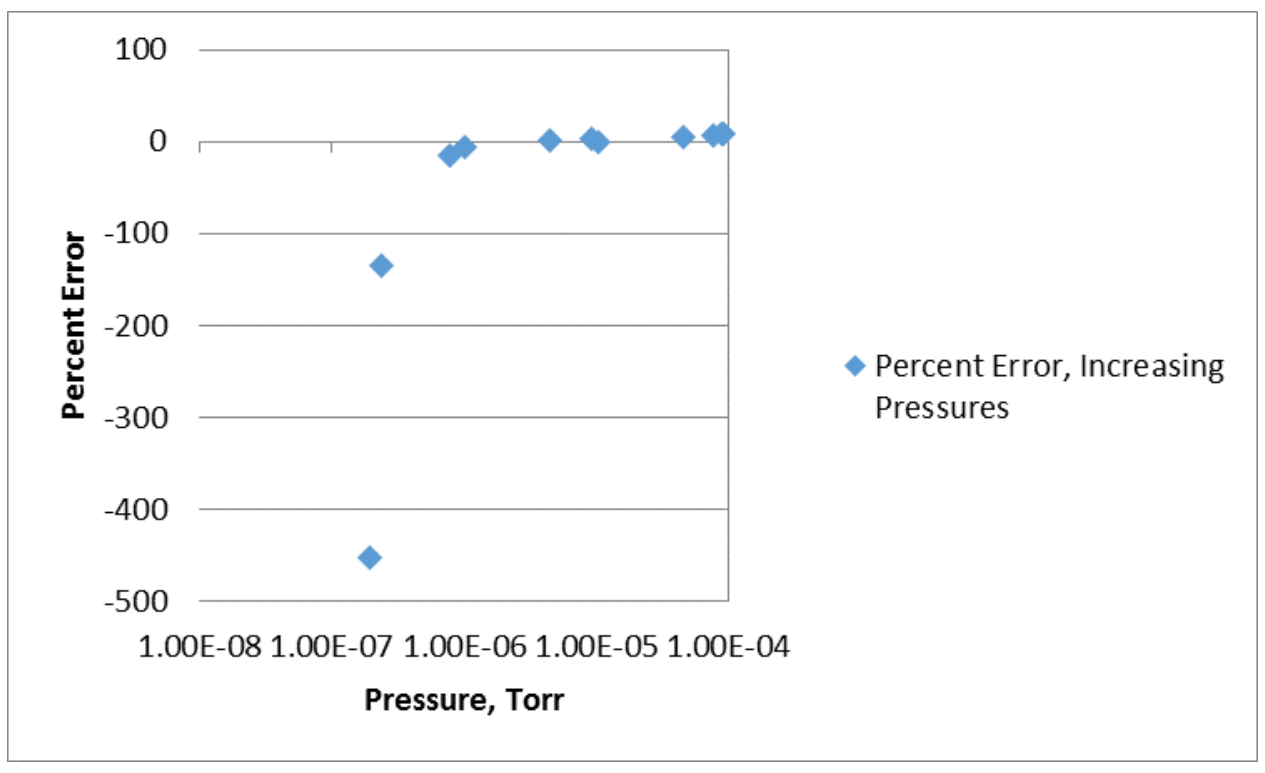

Figure 19. SRG performance for a pressure calibration after a sudden pressure drop was applied to the system, 30 second samples (Comparison of SL-457T to SL-456G standards).

\subsection{Comparison of SRG to IG Performance at Low Pressures}

Figures 9 and 18 were also used to compare IG's to SRG's with respect to measurement performance. Typical pressure vs. measurement errors are shown in Fig. 18, where an SRG was calibrated with an IG standard. By comparison, test results from Fig. 9 showed that ion gauges performed much better at lower pressures with respect to errors.

When an ion gauge was compared to an SRG, the SRG errors were much higher than expected, where vendor literature stated that $U_{R E F}=2.6 \%$ between $1.3 \times 10^{-7}$ and $1.3 \times 10^{-4}$ Torr, during a one year period. SRG experimental percent errors from Fig. 18 were considered along with the NIST calculated uncertainties of Fig. 16. The test results of Fig. 18 were comparable to numerous other tests where sample times longer than 30 seconds were not investigated, since uncertainties started to increase beyond 30 seconds as the system pressure started to drift downward due to pump operations in the system, and zero errors were considered to be acceptable. Overall, IG's provided smaller measurement errors than SRG's during this series of tests at high vacuum. 


\section{FLUID TRANSIENTS}

Fluid transients are reasonably well understood for cases where the fluid is a liquid or gas, which acts as a continuum (Leishear [16]), and the kinetic theory of rarefied gases considers the mechanics of gas flows at low pressures (Vincetti and Kruger [17]). Even so, molecular flow fluid transients are little understood.

Velocities in the tubing can be approximated by Eq. (8) to provide some insight into what happens when pressures are suddenly changed in vacuum systems and gauges. Different gauges can be represented by using tubing diameters and approximate tubing lengths. The initial velocity, $V$, can be determined by combining the cross sectional area, $A$, in $\mathrm{cm}^{2}$ of the tubing with the conductance from Eq. (8) to obtain

$V=\frac{C}{A \cdot 100}=\left\{\frac{135 \cdot d^{4} \cdot\left(\frac{p_{1}+p_{2}}{2}\right)}{L}+\frac{12 \cdot 1 \cdot d^{\mathrm{g}}}{L} \times \frac{1+192 \cdot d \cdot\left(\frac{p_{1}+p_{2}}{2}\right)}{1+237 \cdot d \cdot\left(\frac{p_{1}+p_{2}}{2}\right)} / A\right\}$ meter $/$ second.

Using Eq. (9), the approximate velocity can be determined as gas enters or exits the chamber from different gauges at the time when pressures are suddenly lowered, where $p_{1}$ and $p_{2}$ are assumed to be the pressures in a gauge or in the chamber as applicable. Approximate lengths and diameters were measured from the installed equipment. Table 4 provides calculated initial velocities of gas entering or exiting the chamber to or from different gauges for a single, common set of selected pressures, $p_{1}$ and $p_{2}$.

From the data in Fig.4, note that velocities for different gauge designs are 1000 to 1 million times faster when chamber pressures are decreased in the $1 \times 10^{-4}$ Torr range and $1 \times 10^{-8}$ Torr, respectively. In other words, flow rates are orders of magnitudes smaller at high vacuum. This difference in flow rate is coincident to experimental results to definitively prove that sudden pressure drops cause significant vacuum gauge errors at low pressures. Effectively, the probability of molecules exiting a gauge is higher than the probability of molecules reentering a gauge. Within the gauge and attached tubing, molecules reflect off of the surfaces to collimate the stream of molecules exiting the gauge and increase the average drift velocity of the molecules. Once the molecules exit the gauge into the chamber, this collimation effect that increases the average velocity in a confined space is not present. Gas molecules randomly enter the chamber wall opening into the gauge tubing, and the average velocity is therefore lower when the gauge is filling than when it is venting. These random molecular effects on flow rates are only significant for low pressures coupled with sudden pressure decreases.

Considering the CCG, it has a slower response time to return to equilibrium than ion gauges. The narrow passages and orifice plates found in CCG's provide an explanation for this slower response. Molecular flow is simply more restricted in a CCG than an IG, and the flow rate from the gauge is reduced even further. 
Consider the chamber and gauges to examine these conclusions with respect to pressure drops. When the system is fully evacuated to $\approx 1 \times 10^{-8}$ Torr and then pressurized slowly, the evacuated gauge and chamber fill together, while the gauges fill at slower rates. The chamber is at a higher pressure than the gauges and provides a nearly constant velocity flow into the gauges, since the tank volumes are negligibly affected as indicated by the ratio of gauge volume to chamber volume in Table 4. Each additional calibration is performed in turn until the pressure reaches $1 \times 10^{-4}$ Torr. When the chamber is then suddenly vented back down to $\approx 1 \times 10^{-8}$ Torr, the chamber has no resistive force to flow from the gauges, and the gauges vent their pressure nearly asymptotically. Once gas molecules are removed from a gauge at low pressures due to a pressure surge from the vacuum system, molecules are slow to refill the gauges. The lower gas density in the gauge then affects gauge readings until equilibrium between the chamber and the gauge is reestablished.

\begin{tabular}{|c|c|c|c|c|c|c|c|}
\hline Gauge & $\begin{array}{c}\text { Velocity, } \\
\text { meter/second }\end{array}$ & $\begin{array}{l}\text { Conductance, } \\
\text { liters/second }\end{array}$ & $\begin{array}{c}p_{1}, \\
\text { Chamber } \\
\text { Pressure, } \\
\text { Torr }\end{array}$ & $\begin{array}{c}\mathrm{p}_{2}, \\
\text { Gauge } \\
\text { Pressure, } \\
\text { Torr }\end{array}$ & $\mathrm{d}, \mathrm{cm}$ & $\mathrm{L}, \mathrm{cm}$ & $\begin{array}{c}\text { Ratio of } \\
\text { (Gauge }+ \\
\text { Tubing } \\
\text { Volume) / } \\
\text { (Chamber } \\
\text { Volume) }\end{array}$ \\
\hline IG & 1.270E-06 & 1.217E-03 & 5.95E-08 & 2.49E-08 & 3.493 & 12.700 & 0.0243 \\
\hline SRG & 5.613E-08 & 7.110E-06 & 5.95E-08 & 2.49E-08 & 1.270 & 38.100 & 0.0096 \\
\hline CDG & 1.901E-09 & 1.505E-08 & 5.95E-08 & 2.49E-08 & 0.318 & 71.120 & 0.0011 \\
\hline CCG & 4.886E-07 & $4.681 \mathrm{E}-04$ & $5.95 E-08$ & $2.49 \mathrm{E}-08$ & 3.493 & 33.020 & 0.0632 \\
\hline IG & 6.725E-03 & $6.442 \mathrm{E}+00$ & 5.73E-04 & 1.10E-04 & 3.493 & 12.700 & 0.0243 \\
\hline SRG & 3.336E-04 & 4.226E-02 & 5.73E-04 & 1.10E-04 & 1.270 & 38.100 & 0.0096 \\
\hline CDG & 1.193E-05 & 9.449E-05 & 5.73E-04 & 1.10E-04 & 0.318 & 71.120 & 0.0011 \\
\hline CCG & $2.586 \mathrm{E}-03$ & $2.478 \mathrm{E}+00$ & 5.73E-04 & 1.10E-04 & 3.493 & 33.020 & 0.0632 \\
\hline
\end{tabular}

Table 4. Initial average gas velocities between the gauges and chamber.

Accordingly, transient molecular flows affect the uncertainty and error of the gauges, where experimental testing demonstrated this conclusion. Note that percent errors are discussed throughout this paper to describe pressure measurements. These errors describe percent differences between gauge measurements and system pressures. The gauges measure the actual 
pressures inside the gauges, which differ from the pressures elsewhere in the vacuum system. Significant errors of $80 \%$ were observed for seemingly identical tests.

These percent differences may at first seem to be questionable, but these differences are consistent with theory and practice from other branches of engineering. Vincetti and Kruger [17] observed that low density gas flows can be described by Fick's Law, which was first proposed to describe diffusion in miscible gases and liquids. Since this initial diffusion theory was published, Fick's Law has been used to describe the neutron flux in nuclear reactors and mixing processes. Each of these processes is statistically related due to the random motion of particles in their respective systems. In general, Fick's Law and computer modeling provide approximations for diffusive systems, but research indicates that diffusive systems have very high uncertainties. For example, recent mixing research (Leishear [18]) showed that CFD models predicted average mixing times in thousand gallon tanks within $30 \%$, but the uncertainty, $U$, of those mixing times exceeded more than a $100 \%$. Models are valuable, but actual disparities in physical processes greatly affect the differences between theory and experiments. Although a thorough study of uncertainties was not completed during this research, test results indicated large differences in measurements apparently identical tests, but these differences are consistent with other diffusion research. These observations further demonstrate the validity of molecular flow fluid transient theory. Once again, additional research is warranted.

\section{SUMMARY OF FLUID TRANSIENT ANALYSES}

Having provided a technical explanation of the molecular flow fluid transient phenomenon, a summary of test results is warranted. Percent errors were studied as a means to measure the differences between the performances of different gauges following a transient.

\subsection{IG, SRG and CCG Analysis}

For each gauge design, errors due to transients were noticeable below $\approx 1 \times 10^{-6}$ Torr and increased asymptotically down to a maximum value at the system minimum pressure of $1 \times 10^{-8}$ Torr. Table 5 provides data for the maximum percent errors for a CCG, an SRG, and an IG following sudden pressure decreases in the vacuum system. By providing maximum errors, Table 5 summarizes performance data for different types of gauges. Note that errors in the table decrease in accordance with the complexity of the entrance passages into the gauges. The CCG had the highest errors due to transient pressure drops, where the CCG had the most restrictive entrance passage of the three gauges considered. The SRG has a less restrictive passage to the gauge. The IG has the most open entry passage into the gauge measuring element, and consequently the IG has the lowest error of the IG, SRG, and CCG, following a pressure transient, or fluid transient.

\begin{tabular}{|c|c|c|}
\hline $\begin{array}{c}\text { Gauge } \\
\text { Design }\end{array}$ & $\begin{array}{c}\text { Maximum Calibration Errors Following } \\
\text { a Transient, i.e., }\end{array}$ & Calibration Errors, \\
\hline
\end{tabular}




\begin{tabular}{|c|c|c|c|c|c|c|}
\hline \multirow{2}{*}{} & \multicolumn{3}{|c|}{ Sudden Pressure Decrease } & \multicolumn{3}{c|}{ Pre-transient Conditions, } \\
\cline { 2 - 7 } & Pressure, Torr & Percent Error & Figure & Pressure, Torr & Percent Error & Figure \\
\hline CCG & $1.2 \mathrm{E}-7$ & $-847.4 \%$ & 14 & $1.7 \mathrm{E}-7$ & $12.0 \%$ & 12 \\
\hline SRG & $1.9 \mathrm{E}-7$ & $-452.2 \%$ & 19 & $1.5 \mathrm{E}-7$ & $55.4 \%$ & 18 \\
\hline IG & $1.3 \mathrm{E}-8$ & $-49.8 \%$ & 10 & $3.4 \mathrm{E}-7$ & $5.2 \%$ & 9 \\
\hline CDG & $1.0 \mathrm{E}-4$ & $-6.3 \%$ & 6 & $3.0 \mathrm{E}-4$ & $<0.01 \%$ & 5 \\
\hline
\end{tabular}

Table 5. Maximum measurement errors due to sudden pressure drops for different gauge designs.

Note also that all of the errors for transients are negative in Table 5, when calibrations follow pressure drops. Percent errors were calculated for each gauge in this table with respect to the ion gauge standard. The negative errors therefore demonstrated that fewer molecules remained in the gauges after sudden pressure drops in the vacuum system, since pressures are always significantly lowered following a decreasing pressure transient. Gauge pressures were also shown to drop in Fig. 13.

For comparison, percent errors are presented in Table 5 for conditions at pre-transient conditions when transient effects were not present. That is, there were no sudden pressure drops or increases during calibrations. Note that all gauge errors are smaller when transients are not induced into the vacuum system. These observations provide conclusive evidence that flow exits the gauges and then refills the gauges later to cause incorrect gauge readings until equilibrium is reached in hours or even more than a day later, depending on gauge and system design.

\subsection{CDG Analysis}

CDG's were evaluated with respect to suddenly dropping pressures as noted in Section 6.2, and CDG's were evaluated at pre-transient conditions in Section 6.1. CDG's experienced minor measurement effects due to sudden transients.

Pre-transient and transient CDG test results were compared to demonstrate that sudden pressure drops minimally affected vacuum gauge performance at higher pressures $\left(1 \times 10^{-1} \mathrm{Torr}\right)$. Test results from a 0.1 Torr CDG are shown in Fig. 5 for a gauge that was tested under near equilibrium conditions between $2 \times 10^{-3}$ Torr and $1 \times 10^{-1}$ Torr in the absence of significant transient pressures. To compare this pre-transient data to tests performed following transients, tests were performed within two minutes of fluid transients that dropped the vacuum system pressures through the gauge pressure ranges. For one of these tests, the percent error was $-6.3 \%$ 
at $1 \times 10^{-4}$ Torr. Percent errors were affected by transients, but these errors were within the uncertainties of the tested CDG's within minutes of sudden pressure drops. In other words, there is a minor effect on CDG errors due to pressure transients below $2 \times 10^{-2}$ Torr. In fact, the effects of transients may be one of the system effects, $u_{S Y S}$, inherent in CDG uncertainties $(U$.) Additional research may be warranted to understand minor pressure transient effects on CDG's.

Of greater import to this study however, the flow paths to this CDG consisted of approximately 71 centimeters of 0.318 centimeter diameter tubing, which was of course, the most restrictive flow path of any of the gauge designs under consideration. Even the most restrictive flow paths of the gauges considered during this research did not significantly affect vacuum measurements following sudden system pressure drops for CDG's at higher pressures between $1 \times 10^{-2}$ Torr and 10 Torr, where several CDG's were tested in many calibrations.

\subsection{Summary of Gauge Analyses}

Tests were performed to investigate transient effects on gauge performance with respect to measurement errors, where gauge measurements overshoot actual vacuum system pressures. Although additional research is warranted, sufficient data has been collected to prove the following conclusions.

1) Maximum gauge errors due to sudden pressure drops increased as test pressures approached $1 \times 10^{-8}$ Torr, which was the low pressure limit of the vacuum system used for testing. These errors were caused by fluid transients of molecular flows due to sudden pressure changes.

2) System response and consequent gauge errors were geometry dependent, following sudden pressure decreases in the vacuum system, where

CDG percent error $<$ IG percent error $<$ SRG percent error $<$ CCG percent error.

a. Cold cathode gauges had more restricted flow paths from the calibration chamber into the gauge than spinning rotor gauges, and cold cathode gauges subsequently had larger measurement errors than spinning rotor gauges, following sudden pressure drops.

b. Spinning rotor gauges had more restricted flow paths from the chamber into the gauge than ion gauges, and consequently spinning rotor gauges had larger measurement errors than ion gauges, following sudden pressure drops.

c. Ion gauges had flow paths that were fully open to the vacuum chamber and less restrictive than ion gauges or spinning rotor gauges. Ion gauge measurement errors following sudden pressure drops were consequently smaller than spinning rotor gauge errors or ion gauge errors.

d. At higher pressures $\left(<2 \times 10^{-2}\right.$ Torr $)$, capacitance diaphragm gauges were negligibly affected by sudden pressure drops, even though these gauges had the most 
restricted flow paths of the gauges evaluated. Below $2 \times 10^{-2}$ Torr errors were considered minor for SRSL purposes, but these errors may of more significance to others.

3) Significant measurement errors were not observed when pressures were suddenly increased, although transient effects were noted following suddenly increased pressures. Additional research may be warranted with respect to increasing pressures, since scant research was performed for increasing pressure effects.

4) Additionally, spinning rotor gauge errors increased significantly below $5 \times 10^{-6}$ Torr for all calibration measurements. That is, gauge measurement errors were significant whether or not transients due to sudden pressure drops occurred.

\section{RECOMMENDED CORRECTIVE ACTIONS}

To improve gauge performance at low pressures, several precautions should be observed:

1. To minimize measurement accuracy errors during routine vacuum gauge calibrations at high vacuum, ensure that the system has reached its lower operating limits before performing measurements, validate gauge accuracy before proceeding with calibrations, and then only perform measurements while increasing the system pressures. These actions control fluid transient effects on gauge accuracy when pressures are suddenly decreased.

2. To minimize measurement accuracy errors during vacuum system operations at high vacuum, vacuum system users should evaluate the time required for their system to return to equilibrium, following a fluid transient caused by suddenly decreasing pressures. The effects of system volumes on transients were not evaluated during this research. Again, further research is warranted.

3. Ensure that vacuum systems are at equilibrium before starting a calibration, which may take a day to a week, or so, between calibrations at high vacuums. This delay is a delay in addition to the start-up delay required before initial calibrations that is usually required to outgas the vacuum system, after extended outages when the system is subjected to atmospheric humidity.

4. Reduce pressures slowly when required to minimize vacuum gauge errors.

5. Do not measure vacuum pressures immediately following sudden pressure decreases in a system at high vacuum.

\section{CONCLUSIONS}

In short, molecular flow fluid transients affect measurements from all gauge designs as pressures are suddenly lowered, and these affects are significant at low pressures (high vacuum) where pressures inside the gauges and resultant pressure measurements are temporarily much lower than vacuum system pressures. Conclusive testing proved that sudden pressure drops in vacuum systems affected vacuum gauge measurements for different vacuum gauge designs, such that measurement errors are more influenced for some designs than others. Gauges that were significantly affected included ion gauges, spinning rotor gauges, and cold cathode gauges. In short, uncertainties for these gauges far exceeded manufacturers published uncertainties when pressures were suddenly lowered to high vacuum. The cause of this anomaly is attributed to 
rapid changes in molecular flow and the inability of the vacuum system and gauges to immediately return to equilibrium at low pressures below $\approx 1 \times 10^{-6}$ Torr.

At low pressures, molecules are more likely to exit a gauge into the vacuum system, or calibration chamber, than they are to reenter the gauge, since molecule to molecule collisions are unlikely, and molecular collisions with gauge surfaces collimate molecular flow exiting from the gauges. Consequently, a sudden pressure decrease in the vacuum system, or chamber, results in gauges venting gas molecules faster than they are returned to the gauges when the system is later re-pressurized. That is, non-equilibrium dynamic conditions result in incorrect measurements errors by the vacuum gauges due to fluid, or pressure, transients.

With respect to measurement errors for vacuum pressure gauges, extensive research and analysis concludes that:

1) Sudden pressure drops significantly affect gauge measurements at low pressures below $\approx 1 \times 10^{-6}$ Torr.

2) Measurements for all gauge designs are affected by suddenly decreased pressures in vacuum systems.

3) Vacuum measurements are affected differently for different gauge designs following sudden pressure drops in vacuum systems, where

a) Percent errors compare the performance of different gauge designs, such that $\mathrm{CDG}$ percent error $<\mathrm{IG}$ percent error $<\mathrm{SRG}$ percent error $<\mathrm{CCG}$ percent error.

b) Percent errors are significant for ion gauges (IG's), spinning rotor gauges (SRG's) and cold cathode gauges (CCG's), where many hours may pass before measurements are correct.

c) Percent errors are minor for capacitance diaphragm gauges (CDG's), but errors due to transient effects have been observed up to about $2 \times 10^{-2}$ Torr.

4) SRG's may have significant errors at high vacuum regardless of the occurrence of sudden pressure drops, but these errors may, or may not, be related to inlet piping connected to the gauge.

5) Recommended corrective actions can minimize pressure measurement errors due to sudden pressure drops in vacuum systems.

6) A fundamental mechanism has been identified that increases measurement errors and consequently may affect vacuum system performance. Further research is recommended to better understand these pressure transient effects for different systems and conditions.

\section{ACKNOWLEDGEMENTS}

Jay Bennett and Mark Benner of the Primary Standards Laboratory at Sandia National Laboratories in Albuquerque, New Mexico, and James Fedchak of NIST in Gaithersburg, Maryland are gratefully acknowledged for their contributions with respect to SRG calibrations. Research was performed in the Savannah River Standards Laboratory, which is operated by the Savannah River National Laboratory for the U.S. Department of Energy in Aiken, South Carolina. 


\section{REFERENCES}

[1] ISO/IEC 17025, "General Requirements for the Competence of Testing and Calibration Laboratories," International Organization for Standardization, Geneva, Switzerland, 2005.

[2] JCGM 100, "Evaluation of Measurement Data - Guide to the Expression of Uncertainty in Measurement”, Bureau International des Poids et Mesures, Sevre Cedex, France, 2008.

[3] B. Taylor and C. Kuyatt, "NIST Technical Note 1297, Guidelines for Evaluating and Expressing the Uncertainty of NIST Measurement Results, National Institute of Standards and Technology, Gaithersburg, Maryland, 1994.

[4] ASME B89.7.3.1, "Guidelines for Decision Rules: Considering Measurement Uncertainty in Determining Conformance to Specifications", American Society of Mechanical Engineers, New York, New York, 1989.

[5] H. Colemen and W. Steele Jr., Experimentation and Uncertainty Analysis for Engineers, John Wiley and Sons, New York, New York, 1989.

[6] ISO/TS 3567-2005, "Vacuum gauges, Calibration by direct comparison with a reference gauge", International Organization for Standardization, Geneva, Switzerland.

[7] ISO 27893-2011, "Vacuum technology — Vacuum gauges — Evaluation of the uncertainties of results of calibrations by direct comparison with a reference gauge", International Organization for Standardization, Geneva, Switzerland.

[8] Varian, Inc., Basic Vacuum Practice, Lexington, Massachusetts, 1989.

[9] Boltzman, L., Lectures on Gas Theory, University of California Press, Berkeley, California, 1964.

[10] W. Umrath, Fundamentals of Vacuum Technology, Oerlikon, Cologne, Germany, 2007.

[11] Pfeiffer Vacuum, “The Vacuum Technology Book, "Part 2: Know-how book", http://www.pfeiffervacuum.com (last accessed December 2014).

[12] J. John, 1984, Gas Dynamics, Allyn and Bacon, Newton, Massachusetts.

[13] Omega Engineering, Inc. Stamford, Connecticut, http://www.omega.com/literature /transactions/volume3/high3 .html (last accessed, March, 2015).

[14] Scientific Instrument Services, Ringoes, New Jersey, http://www.sisweb.com/vacuum/sis /inlinga.htm (last accessed March 2015).

[15] Kurt J. Lesker Company, "Pressure Measurement Technical Notes," Pittsburg, Pennsylvania, http://www.lesker.com/newweb/gauges/gauges_technicalnotes_1.cfm, (last accessed December 2014).

[16] R. Leishear, Fluid Mechanics, Water Hammer, Dynamic Stresses, and Piping Design, American Society of Mechanical Engineers, New York, New York, 2013.

[17] Vincetti, W. G. and Kruger, Jr., C. H., Introduction to Physical Gas Dynamics, Wiley, New York, New York, 1965.

[18] Leishear, R., "CFD and Safety Factors”, Mechanical Engineering Magazine, ASME Press, American Society of Mechanical Engineers, New York, New York, 2013. 